\title{
Order and disorder in quaternary atomic laminates from first-principles calculations
}

\author{
Martin Dahlqvist and Johanna Rosén
}

\section{Linköping University Post Print}

\section{Tweet}

N.B.: When citing this work, cite the original article.

Original Publication:

Martin Dahlqvist and Johanna Rosén, Order and disorder in quaternary atomic laminates from first-principles calculations, 2015, Physical Chemistry, Chemical Physics - PCCP, (17), 47, 31810-31821.

http://dx.doi.org/10.1039/c5cp06021d

Copyright: Royal Society of Chemistry

http://www.rsc.org/

Postprint available at: Linköping University Electronic Press

http://urn.kb.se/resolve?urn=urn:nbn:se:liu:diva-123850 


\section{Physical Chemistry Chemical Physics}

\section{ARTICLE}

\section{Order and disorder in quaternary atomic laminates from first- principles calculations}

Received 00th January 20xx, Accepted 00th January 20xx

DOI: $10.1039 / \times 0 \times x 00000 x$

www.rsc.org/

\begin{abstract}
Martin Dahlqvist* and Johanna Rosen
We report on the phase stability of chemically ordered and disordered quaternary MAX phases $-\mathrm{TiMAIC}_{1} \mathrm{Ti}_{2} \mathrm{AIC} \mathrm{C}_{2}$ $M \mathrm{Ti}_{2} \mathrm{AlC}_{2}$, and $\mathrm{Ti}_{2} \mathrm{M}_{2} \mathrm{AlC}_{3}$ where $M=\mathrm{Zr}$, Hf (group IV), $M=\mathrm{V}, \mathrm{Nb}, \mathrm{Ta}$ (group V), and $M=\mathrm{Cr}, \mathrm{Mo}, \mathrm{W}$ (group VI). At $0 \mathrm{~K}$, layered chemically ordered structures are predicted to be stable for $M$ from group $\mathrm{V}$ and $\mathrm{VI}$. By taking into account the configurational entropy, an order-disorder temperature $T_{\text {disorder }}$ can be estimated. $\mathrm{Ti}_{2} \mathrm{AlC}_{2}(\mathrm{M}=\mathrm{Cr}, \mathrm{Mo}, \mathrm{W})$ and Ti ${ }_{2} \mathrm{M}_{2} \mathrm{AlC}_{3}$ $(M=\mathrm{Mo}, \mathrm{W})$ are found with $T_{\text {disorder }}>1773 \mathrm{~K}$ and are hence predicted to be ordered at the typical bulk synthesis temperatures of $1773 \mathrm{~K}$. Other ordered phases, even though metastable at elevated temperatures, may be synthesized by non-equilibrium methods such as thin film growth. Furthermore, phases predicted not to be stable in any form at $0 \mathrm{~K}$ can be stabilized at higher temperatures in a disordered form, being the case for group IV, for $M \mathrm{Ti}_{2} \mathrm{AlC}_{2}(\mathrm{M}=\mathrm{V}, \mathrm{Cr}, \mathrm{Mo})$, and for $\mathrm{Ti}_{2} \mathrm{M}_{2} \mathrm{AlC}_{3}$ $(M=\mathrm{V}, \mathrm{Ta})$. The stability of the layered ordered structures with $M$ from group $\mathrm{VI}$ can primarily be explained by Ti breaking the energetically unfavorable stacking of $M$ and $C$ where $M$ is surrounded by $C$ in a face-centered cubic configuration, and by $M$ having a larger electronegativity than Al resulting in fewer electrons available for populating antibonding Al-Al orbitals. The results show that these chemically ordered quaternary MAX phases allow for new elemental combinations in MAX phases, which can be used to add new properties to this family of atomic laminates and in turn prospects for tuning these properties.
\end{abstract}

\section{Introduction}

Atomic laminates with the general formula $M_{n+1} A X_{n}(n=1-3)$, where $M$ is an early transition metal, $A$ is a group 13 to 16 element, and $X$ is carbon and/or nitrogen, have attracted interest due to their combination of attributes from metals and ceramics such as good machinability, electrical and thermal conduction, heat and oxidation resistance, damage tolerance, and a maintained strength at high temperatures. ${ }^{1,2}$ Recently also magnetism was been added to the long list of attainable properties for these so-called MAX phases. ${ }^{3,4}$

To date $\sim 70$ ternary MAX phases have been synthesized with $\mathrm{Nb}_{2} \mathrm{GeC}^{5}$ and $\mathrm{Mn}_{2} \mathrm{GaC}^{6,7}$ being among the latest additions to this family of compounds. Adding a fourth element by alloying on the $M-A$ - and/or $X$ site allows for even more elemental combinations. In particular, solid solutions on the $M$-site include, e.g., $(\mathrm{Ti}, M)_{2} \mathrm{AlC}$ where $M=\mathrm{V}, \mathrm{Nb}, \mathrm{Ta}, \mathrm{Cr},{ }^{8-11}(\mathrm{~V}, M)_{2} \mathrm{AlC}$ where $M=\mathrm{Nb}, \mathrm{Ta}, \mathrm{Cr},{ }^{9,12}(\mathrm{Cr}, \mathrm{Mn}){ }_{2} A \mathrm{C}$ where $A=\mathrm{Al}, \mathrm{Ga}, \mathrm{Ge},{ }^{3,13-}$ $19(\mathrm{Ti}, \mathrm{V})_{3} A \mathrm{C}_{2}$ where $A=\mathrm{Al}, \mathrm{Ge},{ }^{20,21}$ and $(\mathrm{V}, M)_{4} \mathrm{AlC}_{3}$ where $M=$ $\mathrm{Ti}, \mathrm{Nb}{ }^{20}, 21$ Adding a fourth element has also been demonstrated by realization of $\mathrm{TiCr}_{2} \mathrm{AlC}_{2}, 22,23 \mathrm{~V}_{1.5} \mathrm{Cr}_{1.5} \mathrm{AlC}_{2},{ }^{12}$ $\mathrm{TiMo}_{2} \mathrm{AlC}_{2},{ }^{24}, 25$ and $\mathrm{Ti}_{2} \mathrm{Mo}_{2} \mathrm{AlC}_{3},{ }^{24}$ which all are recent discoveries of chemically ordered quaternary MAX phases, with

Thin Film Physics Division, Department of Physics, Chemistry and Biology (IFM), Linköping University, SE-581 83 Linköping, Sweden. E-mail: martin.dahlqvist@liu.se

Electronic Supplementary Information (ESI) available: Detailed information of considered spin configurations used to model $\mathrm{Cr}$-based $\mathrm{MAX}$ phase and considered atomic stackings for MC and MAX phases. See DOI: 10.1039/x0xx00000x atomic layers composed of a single element only. This raises the question why certain combinations of $M$ elements form layered chemically ordered MAX phases, while other combinations result in a solid solution. In both cases, new alloys may allow incorporation of elements beside those included to date which, in turn, may enable addition of new properties and prospects for tuning these properties. Furthermore, novel MAX phase alloys may allow realization of new 2D counterparts, so called MXenes, ${ }^{26}$ from chemical etching of the $A$-layer.

In this work, we have performed first-principles calculations on $(\mathrm{Ti}, M)_{n+1} \mathrm{AlC}_{n}$ phases $(n=1-3)$, to explore chemically ordered and disordered distributions of Ti and $M$ on the $M$-site for $M=\mathrm{Zr}, \mathrm{Hf}, \mathrm{V}, \mathrm{Nb}, \mathrm{Ta}, \mathrm{Cr}$, Mo, W. This allows a systematic investigation with $M$ elements spanning over group IV, $\mathrm{V}$, and $\mathrm{VI}$ and period 4, 5, and 6 in the periodic table of elements. $A$ is kept equal to $\mathrm{Al}$, since i) all chemically ordered MAX phase alloys reported to date include $A=A l, 12,22-25$ i.e. this choice allows theoretical validation of previous experimental results as well as prediction of new alloys, and ii) to date, all known MXenes originate from chemical etching of Al from a MAX phase, ${ }^{26}$ with the only exception of $\mathrm{Mo}_{2} \mathrm{C},{ }^{27}$ i.e. here predicted new alloys implies potentially new MXenes. Recently, chemically ordered MXenes were produced from chemically ordered quaternary MAX phases. ${ }^{28}$

This study is divided into two parts. In the first part, we perform explanatory and predictive calculations with respect to stability of chemically ordered as well as disordered quaternary MAX phases. The calculations confirm the stability of the quaternary phases reported to date, and also suggest several ordered as well as disordered novel alloys. In the second part, 
the driving force behind the formation of the layered chemically ordered MAX phases is discussed in terms of atomic stacking sequences of $M$ and $C$, electronegativity of $M$ and $A l$, and the electronic structure and chemical bonding between the constituting elements.

\section{Computational Methods}

First-principles calculations were performed by means of density functional theory (DFT) and the projector augmented wave method ${ }^{29}, 30$ as implemented within the Vienna ab-initio simulation package (VASP). ${ }^{31-33}$ We adopted the generalized gradient approximation (GGA) as parameterized by PerdewBurke-Ernzerhof $(\mathrm{PBE})^{34}$ for treating electron exchange and correlation effects. A plane-wave energy cut-off of $400 \mathrm{eV}$ was used and for sampling of the Brillouin zone we used the Monkhorst-Pack scheme. ${ }^{35}$ For each considered phase the calculated total energy is converged to within $0.5 \mathrm{meV} / \mathrm{atom}$ with respect to $k$-point sampling and structurally optimized in terms of unit-cell volumes, $c / a$ ratios (when necessary), and internal parameters to minimize the total energy.

For all $(\mathrm{Ti}, M)_{n+1} \mathrm{AlC}_{n}$ compositions, we considered different layered chemically ordered structures, hereafter referred to as just ordered structures, defined in Fig. 1 for $n=1$ with Ti:M $=1: 1$ (type A, B, C, D), $n=2$ with Ti:M = 2:1 and 1:2 (type A, B, C, D, E, $\mathrm{F}$ ), and $n=3$ with Ti:M $=2: 2$ composition (type A, B). Spinpolarization have been considered for $\mathrm{Cr}$-based phases in the form of non-magnetic (NM), ferromagnetic (FM) and up to five different antiferromagnetic (AFM) spin configurations for each ordered structure. Detailed information of these spin configurations are given in Table S1 to S10.

Chemically disordered structures, hereafter referred to as just disordered structures, denote a solid solution of $M$ and $\mathrm{Ti}$ on the $M$-sites. These are modelled using the special quasirandom structure (SQS) method ${ }^{36,37}$ on supercells of $4 \times 4 \times 1$ $M_{2} A X, M_{3} A X_{2}$, and $M_{4} A X_{3}$ unit cells, with a total of 64,96 , and $128 M$-sites, respectively. Convergence tests with respect to total energy show that these sizes are appropriate to use, based on an energy of the $4 \times 4 \times 1$ unit cells being within $2 \mathrm{meV} /$ atom compared to larger supercells.

For a MAX phase to be thermodynamically stable its energy $E(M A X)$ should be lower than the energy of any linear combination of all other competing phases in the system which corresponds to the MAX phase stoichiometry, i.e.,

$$
\Delta H_{\mathrm{cp}}=E(M A X)-E(\text { competing phases })<0,
$$

where $\Delta H_{\mathrm{cp}}$ is the formation enthalpy. In order to identify the set of most competing phases at a given composition we make use of a linear optimization procedure ${ }^{37,38}$ which have been proven successful to confirm already experimentally known MAX phases as well as predicting the existence of new ones. ${ }^{3,5}$, $6,14,38,39$

When the temperature $T \neq 0 \mathrm{~K}$, Gibbs free energy of a disordered phase, $\Delta G_{\mathrm{cp}}^{\text {disorder }}$, can be approximated using

$$
\Delta G_{\mathrm{cp}}^{\text {disorder }}=\Delta H_{\mathrm{cp}}^{\text {disorder }}-T \Delta S,
$$

where $\Delta S$ is the entropy per formula unit of an ideal solution of Ti and $M$ atoms on the $M$-sites, expressed as

$$
\Delta S=-y k_{B}[z \ln (z)+(1-z) \ln (1-z)],
$$

where $y$ is number of $M$-sites per formula unit, i.e., $y=n+1$, and $z=M /(M+\mathrm{Ti})$.

Chemical bonding was investigated in terms of projected crystal orbital Hamiltonian populations ( $\mathrm{pCOHP}$ ) which were derived using the LOBSTER program. ${ }^{40-42}$ Using this method the calculated band-structure energy is reconstructed into orbital interactions. Positive $\mathrm{pCOHP}$ values indicate an anti-bonding interaction, and negative pCOHP values indicate a bonding interaction.
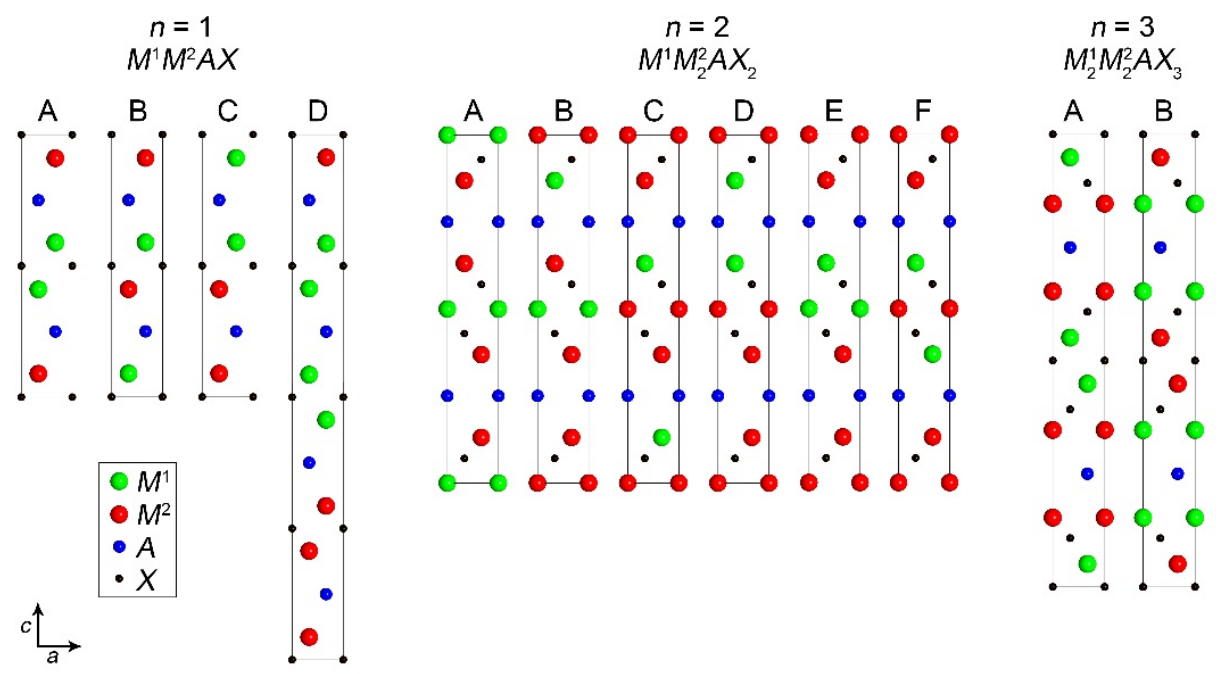

Fig. 1 Schematic illustration of ordered type structures considered for $(\mathrm{Ti}, M)_{n+1} \mathrm{AlC} C_{n}$ where $n=1-3$. These projections are viewed along the $[1 \overline{2} 10]$ direction. 


\section{Results and Discussion}

\subsection{Phase stability of known and hypothetical MAX phase alloys}

The formation enthalpy $\Delta H_{\mathrm{cp}}$ for ordered and disordered configurations of $\mathrm{Ti}$ and $M$ on the $M$-site (ordered type structures as shown in Fig. 1 ) has been calculated for MTiAIC, $\mathrm{TiM}_{2} \mathrm{AlC}_{2}, \mathrm{MTi}_{2} \mathrm{AlC}_{2}$, and $\mathrm{Ti}_{2} \mathrm{M}_{2} \mathrm{AlC}_{3}$ compositions. The results are listed in Table 1 to 4, respectively, along with the identified set of most competing phases (the last column of each table). For $\mathrm{Cr}$-based phases, the spin configuration of lowest energy is presented and specified. For a systematic analysis including identification of trends, selected results are also displayed in Fig 2 to 4 .

Throughout this section, the stability of ordered and disordered structures will be discussed. At $0 \mathrm{~K}$, the structure with lowest energy is considered stable if $\Delta H_{\mathrm{cp}}<0$. However, when $T \neq 0 \mathrm{~K}$, the configurational entropy $\Delta S$ will decrease the free energy for the solid solutions, $\Delta G_{\mathrm{cp}}^{\text {disorder }}$. By using Eq. 2 and 3 , an order-disorder temperature $T_{\text {disorder }}$ can be calculated for which $\Delta G_{\mathrm{cp}}^{\text {disorder }}[T]=\Delta H_{\mathrm{cp}}^{\text {order }}$ is fulfilled, and hence give an estimate above which temperature the disordered structure is energetically favourable. This temperature can then be compared to experimental conditions used, e.g., typical bulk synthesis temperatures of $1200-1600{ }^{\circ} \mathrm{C}$ $(1473-1873 \mathrm{~K})$. We have chosen $1500^{\circ} \mathrm{C}(1773 \mathrm{~K})$ as a reference temperature for estimating preferred order or disorder in an alloy. Hence, for $\Delta H_{\mathrm{cp}}^{\text {order }}<0$ and $T_{\text {disorder }}>1773 \mathrm{~K}$, the ordered structure is predicted to be the most likely outcome in bulk synthesis. If $\Delta H_{\mathrm{cp}}^{\text {order }}<0$ and $T_{\text {disorder }}<1773 \mathrm{~K}$, a resulting disordered structure is suggested. However, it should be stressed that use of reduced synthesis temperature or techniques based on different synthesis kinetics, such as thin film growth, may allow realization of stable as well as metastable phases, i.e. ordered phases with low critical temperatures or even with $\Delta H_{\mathrm{cp}}$ or $\Delta G_{\mathrm{cp}}>0$.

\section{TiMAIC}

Figure 2 (based on Table I) shows the formation enthalpies $\Delta H_{\mathrm{cp}}$ as function of $M$ in TiMAIC for the ordered structure of lowest energy (black bars) and for a solid solution of $\mathrm{Ti}$ and $M$ (red bars). Only $M$ from group $\mathrm{V}$ are found to give $\Delta H_{\mathrm{cp}}<0$, and these phases are hence predicted to be stable. The lowest energies are obtained for the ordered structures, however, at elevated temperatures the free energy for the solid solution, $\Delta G_{\mathrm{cp}}^{\text {disorder }}$, may be reduced to values below $\Delta H_{\mathrm{cp}}$. The temperatures that fulfils $\Delta G_{\mathrm{cp}}^{\text {disorder }}[T]=\Delta H_{\mathrm{cp}}^{\text {order }}$ are plotted as open squares in Fig. 2. For all $M$, the temperature needed to fulfil this criteria is $T<650 \mathrm{~K}$, which is significantly below 1773 $\mathrm{K}$. A disordered distribution of $\mathrm{Ti}$ and $M$ is therefore expected in material synthesis. The here predicted disordered and stable 211 MAX phase alloys including $M=\mathrm{V}, \mathrm{Nb}$, and Ta are consistent with reported bulk synthesis of $\left(\mathrm{Ti}_{0.5} \mathrm{~V}_{0.5}\right)_{2} \mathrm{AIC},{ }^{8}, 9, \quad 11,43$ $\left(\mathrm{Ti}_{0.5} \mathrm{Nb}_{0.5}\right)_{2} \mathrm{AlC},{ }^{9}, 10,44$ and $\left(\mathrm{Ti}_{0.4} \mathrm{Ta}_{0.6}\right)_{2} \mathrm{AlC} \mathrm{MAX}$ phases, ${ }^{9}$ all displaying solid solutions of $M$ and Ti.
If $\quad \Delta H_{\mathrm{cp}}^{\text {order }}>\Delta H_{\mathrm{cp}}^{\text {disorder }}>0, \quad$ the order-disorder temperature becomes negative and hence unphysical. For such situation the temperature for which $\Delta G_{\mathrm{cp}}^{\text {disorder }}[T]=0$ is

Table 1 Calculated formation enthalpy $\Delta H_{\text {cp }}$ for TiMAIC where $M=\mathrm{Zr}, \mathrm{Hf}, \mathrm{V}, \mathrm{Nb}, \mathrm{Ta}, \mathrm{Cr}$, Mo, $\mathrm{W}$, including ordered (type $\mathrm{A}$ to $\mathrm{D}$, shown in Fig. 1 , with $M^{1}=\mathrm{Ti}$ and $M^{2}=M$ ) and disordered (SQS) distribution of $\mathrm{Ti}$ and $M$ on the $M$-site. The last column shows the identified set of most competing phases. See Table S1 to S4 for definition of considered spin configurations for TiCrAlC.

\begin{tabular}{ccccccl}
\hline \multirow{2}{*}{$M$} & \multicolumn{4}{c}{$\Delta H_{\text {cp }}$ (meV/atom) } & \multicolumn{2}{l}{ Identified set of most } \\
competing phases
\end{tabular}

a NM spin configuration of lowest energy.

b in-AFM1 spin configuration of lowest energy. $\mathrm{c}$ in-AFM2 spin configuration of lowest energy. d in-AFM1 spin configuration of lowest energy. e FM spin configuration of lowest energy.

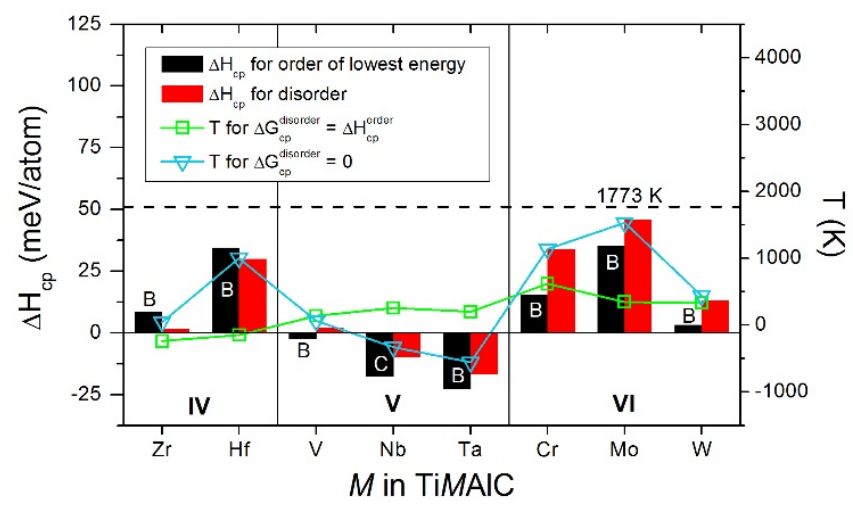

Fig. 2 Formation enthalpy $\Delta H_{\text {cp }}$ for MTiAIC, for the ordered structure of lowest energy (black bar) and the disordered structure (red bar), together with the estimated temperature for which the disordered structure is stabilized, $T_{\Delta G=0}$ (open triangles), and the temperature above which the disordered structure is energetically favourable compared to the ordered one, $T_{\text {disorder }}$ (open squares). The dashed horizontal line represents a typical bulk synthesis temperature of $1773 \mathrm{~K}$

fulfilled, denoted $T_{\Delta G=0}$, is more relevant as it indicates above which temperature the disordered alloy becomes stable (i.e. with a negative formation free energy). This is shown as open triangles in Fig. 2. The disordered structure of both TiZrAIC and TiWAIC are found with positive, though close to zero, values of $\Delta H_{\mathrm{cp}}^{\text {disorder }},+1$ and $+13 \mathrm{meV} /$ atom, respectively. Hence, the disordered structures of these phases are in theory stabilized for temperatures above 49 and $441 \mathrm{~K}$, respectively, and may therefore be possible to synthesize.

\section{$\mathrm{MTi}_{2} \mathrm{AlC}_{2}$ and $\mathrm{TiM}_{2} \mathrm{AlC}_{2}$}

Fig. 3(a) shows $\Delta H_{\mathrm{cp}}$ for $\mathrm{MTi}_{2} \mathrm{AlC}_{2}$, for the layered ordered structures of lowest energy (black bars) and for a solid solution of $\mathrm{Ti}$ and $M$ on the $M$-site (red bars), together with the estimated temperature above which the disordered structure is 
energetically favourable compared to the ordered one, $T_{\text {disorder, }}$ and $T_{\Delta G=0}$ for which the disordered structure is stabilized. Corresponding information for $\mathrm{TiM}_{2} \mathrm{AlC}_{2}$ is plotted in panel (b).

For $M \mathrm{Ti}_{2} \mathrm{AlC}_{2}, M=\mathrm{Nb}, \mathrm{Ta}$, and $\mathrm{W}$ have $\Delta H_{\mathrm{cp}}^{\text {order }}<0$ for ordered structures, suggesting that these phases are stable. However, the configurational entropy will decrease the free energy for the solid solutions, and make the disordered $M \mathrm{Ti}_{2} \mathrm{AlC}_{2}$ compositions for $M=\mathrm{Nb}, \mathrm{Ta}$, and $\mathrm{W}$ energetically favourable for temperatures below typical bulk synthesis temperature, i.e., $T_{\text {disorder }}<1773 \mathrm{~K}$. It should be noted that even though $\Delta H_{\mathrm{cp}}^{\text {order }}>0$ for $\mathrm{ZrTi}_{2} \mathrm{AlC}_{2}, \mathrm{HfTi}_{2} \mathrm{AlC}_{2}, \mathrm{VTi}_{2} \mathrm{AlC}_{2}$, $\mathrm{CrTi}_{2} \mathrm{AlC}_{2}$, and $\mathrm{MoTi}_{2} \mathrm{AlC}_{2}$, these solid solutions may be realized for elevated temperatures through a stabilizing Gibbs free energy as is indicated by blue triangles with $T_{\Delta G=0}<1637 \mathrm{~K}$, i.e. these phases are likely to be found experimentally. Although the stoichiometry is slightly off from $\mathrm{VTi}_{2} \mathrm{AlC}_{2}$, this prediction can be compared to the experimentally obtained $\left(\mathrm{V}_{0.5} \mathrm{Ti}_{0.5}\right)_{3} \mathrm{AlC}_{2}$ solid solution. ${ }^{21}$

For TiM $\mathrm{AlC}_{2}$ in Fig. 3(b), $M$ from group $\mathrm{V}$ and $\mathrm{VI}$ are found with $H_{\mathrm{cp}}^{\text {order }}<0$, indicating stable ordered phases. Two regimes of $T_{\text {disorder }}$ is found where (i) $M$ from group IV and $V$ have $T_{\text {disorder }}<900$ suggesting a preferred solid solution of Ti and $M$, and (ii) $M$ from group VI have $T_{\text {disorder }}>3600 \mathrm{~K}$, indicating that ordered structures are expected at typical synthesis temperatures. For Group $\mathrm{VI}$, type A layering is of lowest energy. Experimental findings of $\mathrm{TiCr}_{2} \mathrm{AlC}_{2}{ }^{22,23}$ and $\mathrm{TiMo}_{2} \mathrm{AlC}_{2}{ }^{24,25}$ with identified structures of type $\mathrm{A}$ corroborates these theoretical predictions. The here predicted stable ordered $\mathrm{TiW}_{2} \mathrm{AlC}_{2}$ is yet to be experimentally verified. Furthermore, even though $\mathrm{TiZr}_{2} \mathrm{AlC}_{2}$ is found with $H_{\mathrm{cp}}^{\text {order }}>0$, the disordered structure is estimated to be stabilized above $1464 \mathrm{~K}$. d FM spin configuration of lowest energy.

e AFM1 spin configuration of lowest energy.

${ }^{f} F M$ spin configuration of lowest energy (NM, AFM1, in-AFM1, and in-AFM2 within $1 \mathrm{meV} /$ atom).

${ }^{g} \mathrm{FM}$ spin configuration of lowest energy.

Table 3 Calculated formation enthalpy $\Delta H_{\mathrm{cp}}$ for $\mathrm{Ti}_{2} \mathrm{AlC}_{2}$ where $M=\mathrm{Zr}, \mathrm{Hf}, \mathrm{V}, \mathrm{Nb}, \mathrm{Ta}$, $\mathrm{Cr}$, Mo, $\mathrm{W}$, including ordered (type $\mathrm{A}$ to $\mathrm{F}$, shown in Fig. 1 with $M^{1}=\mathrm{Ti}$ and $M^{2}=M$ ) and disordered (SQS) distribution of $\mathrm{Ti}$ and $M$ on the $M$-site. The last column shows the identified set of most competing phases. See Table S7 to $S 8$ for definition of considered spin configurations for $\mathrm{TiCr}_{2} \mathrm{AlC}_{2}$.

\begin{tabular}{|c|c|c|c|c|c|c|c|c|}
\hline \multirow{2}{*}{$M$} & \multicolumn{7}{|c|}{$\Delta H_{\mathrm{cp}}$ (meV/atom) } & \multirow{2}{*}{$\begin{array}{l}\text { Identified set of } \\
\text { most competing } \\
\text { phases }\end{array}$} \\
\hline & A & B & C & D & $E$ & $\mathrm{~F}$ & sQS & \\
\hline $\mathrm{Zr}$ & 56 & 46 & 34 & 37 & 48 & 35 & 40 & $\mathrm{Zr}_{3} \mathrm{AlC}_{2}, \mathrm{Ti}_{3} \mathrm{AlC}_{2}$ \\
\hline $\mathrm{Hf}$ & 91 & 73 & 55 & 56 & 74 & 55 & 64 & $\begin{array}{l}\mathrm{TiAl}_{1} \mathrm{Hf}_{2} \mathrm{Al}, \mathrm{HfAl}_{2}, \\
\mathrm{Ti}_{4} \mathrm{AlC}_{3}\end{array}$ \\
\hline v & -8 & 9 & 20 & 30 & 21 & 26 & 16 & $\begin{array}{l}\mathrm{V}_{2} \mathrm{AlC}, \mathrm{Ti}_{2} \mathrm{~V}_{2} \mathrm{AlC}_{3} \\
\text { (A) }\end{array}$ \\
\hline $\mathrm{Nb}$ & -13 & 4 & 14 & 21 & 13 & 13 & 4 & $\begin{array}{l}\mathrm{Ti}_{2} \mathrm{Nb}_{2} \mathrm{AlC}_{3}(\mathrm{~A}) \\
\mathrm{Nb}_{2} \mathrm{AlC}\end{array}$ \\
\hline $\mathrm{Ta}$ & -7 & 1 & 1 & 11 & 12 & -4 & -7 & $\begin{array}{l}\mathrm{TaTi}_{2} \mathrm{AlC}_{2}(\mathrm{~A}), \\
\mathrm{Ta}_{12} \mathrm{Al}_{3} \mathrm{C}_{8}, \\
\left(\mathrm{Ti}_{0.5} \mathrm{Ta}_{0.5}\right) \mathrm{C}, \mathrm{TaAl}_{3}\end{array}$ \\
\hline $\mathrm{Cr}$ & $-3^{a}$ & $66^{b}$ & $141^{c}$ & $139^{d}$ & $79^{e}$ & $135^{f}$ & $98^{\mathrm{g}}$ & $\mathrm{TiC}, \mathrm{Cr}_{2} \mathrm{AlC}$ \\
\hline Mo & -18 & 72 & 159 & 167 & 116 & 154 & 102 & $\begin{array}{l}\mathrm{Ti}_{2} \mathrm{Mo}_{2} \mathrm{AlC}_{3}(\mathrm{~A}), \\
\mathrm{Mo}_{3} \mathrm{Al}, \mathrm{Mo}_{3} \mathrm{Al}_{8}, \mathrm{C}\end{array}$ \\
\hline w & -3 & 81 & 161 & 174 & 156 & 171 & 108 & $\begin{array}{l}\mathrm{Ti}_{2} \mathrm{~W}_{2} \mathrm{AlC}_{3}(\mathrm{~A}), \\
\mathrm{WC}, \mathrm{W}, \mathrm{WAI}_{5}\end{array}$ \\
\hline
\end{tabular}

a in-AFM1 spin configuration of lowest energy.

${ }^{b}$ FM spin configuration of lowest energy.

c AFM3 spin configuration of lowest energy (FM and AFM1 within $1 \mathrm{meV} /$ atom).

d FM spin configuration of lowest energy.

e AFM2 and AFM3 spin configuration degenerate and of lowest energy (FM within $1 \mathrm{meV} /$ atom).

${ }^{f}$ AFM1 spin configuration of lowest energy (FM within $1 \mathrm{meV} /$ atom). $\mathrm{g} F \mathrm{M}$ spin configuration of lowest energy.

Table 2 Calculated formation enthalpy $\Delta H_{\text {cp }}$ for $M \mathrm{Mi}_{2} \mathrm{AlC}_{2}$ where $\mathrm{M}=\mathrm{Zr}, \mathrm{Hf}, \mathrm{V}, \mathrm{Nb}, \mathrm{Ta}$, $\mathrm{Cr}$, Mo, $\mathrm{W}$, including ordered (type $\mathrm{A}$ to $\mathrm{F}$, shown in Fig. 1 with $M^{1}=M$ and $M^{2}=\mathrm{Ti}$ ) and disordered (SQS) distribution of $\mathrm{Ti}$ and $M$ on the $M$-site. The last column shows the identified set of most competing phases. See Table $S 5$ to $S 6$ for definition of considered spin configurations for $\mathrm{CrTi}_{2} \mathrm{AlC}_{2}$.

\begin{tabular}{|c|c|c|c|c|c|c|c|c|}
\hline \multirow[b]{2}{*}{ M } & \multicolumn{7}{|c|}{$\Delta H_{\mathrm{cp}}$ (meV/atom) } & \multirow{2}{*}{$\begin{array}{l}\text { Identified set of } \\
\text { most competing } \\
\text { phases }\end{array}$} \\
\hline & A & B & C & D & $E$ & $\mathrm{~F}$ & SQS & \\
\hline $\mathrm{Zr}$ & 34 & 42 & 50 & 52 & 45 & 52 & 44 & $\mathrm{Ti}_{3} \mathrm{AlC}_{2}, \mathrm{Zr}_{3} \mathrm{AlC}_{2}$ \\
\hline $\mathrm{Hf}$ & 17 & 34 & 51 & 52 & 36 & 51 & 39 & $\mathrm{HfC}, \mathrm{Ti}_{2} \mathrm{AlC}$ \\
\hline V & 26 & 14 & 3 & 6 & 22 & 7 & 11 & $\begin{array}{l}\mathrm{Ti}_{3} \mathrm{AlC}_{2}, \mathrm{TiV}_{2} \mathrm{AlC}_{2} \\
\text { (A) }\end{array}$ \\
\hline $\mathrm{Nb}$ & 3 & -1 & -1 & -5 & 19 & 4 & 0 & $\begin{array}{l}\mathrm{TiNb}_{2} \mathrm{AlC}_{2}(\mathrm{~A}) \\
\mathrm{Ti}_{3} \mathrm{AlC}_{2}\end{array}$ \\
\hline Та & -30 & -19 & -5 & -6 & 7 & 1 & -15 & $\begin{array}{l}\mathrm{TiTa}_{2} \mathrm{AlC}_{2}(\mathrm{~A}) \\
\mathrm{Ti}_{3} \mathrm{AlC}\end{array}$ \\
\hline $\mathrm{Cr}$ & $111^{\mathrm{a}}$ & $62^{b}$ & $6^{c}$ & $13^{d}$ & $82^{e}$ & $14^{f}$ & $45^{g}$ & $\begin{array}{l}\mathrm{TiC}, \mathrm{Cr}_{2} \mathrm{Al}, \mathrm{TiAl}_{3} \\
\mathrm{TiCr}_{2} \mathrm{AlC}_{2} \text { (A) }\end{array}$ \\
\hline Mo & 91 & 55 & 9 & 24 & 108 & 14 & 31 & $\mathrm{TiC}, \mathrm{Mo}_{3} \mathrm{Al}, \mathrm{Mo}_{3} \mathrm{Al}_{8}$ \\
\hline W & 39 & 22 & -8 & 14 & 84 & -7 & -5 & $\begin{array}{l}\mathrm{Ti}_{2} \mathrm{~W}_{2} \mathrm{AlC}_{3}(\mathrm{~A}) \\
\mathrm{Ti}_{3} \mathrm{AlC}_{2}, \mathrm{~W}, \mathrm{WAl}_{5}\end{array}$ \\
\hline
\end{tabular}

a in-AFM2 spin configuration of lowest energy (FM, AFM1, and in-AFM1 within $1 \mathrm{meV} /$ atom).

${ }^{b} \mathrm{FM}$ spin configuration of lowest energy (AFM1, in-AFM1 and in-AFM2 within 1 meV/atom).

c NM spin configuration of lowest energy (FM, AFM1, in-AFM1, and in-AFM2 within $1 \mathrm{meV} /$ atom). 

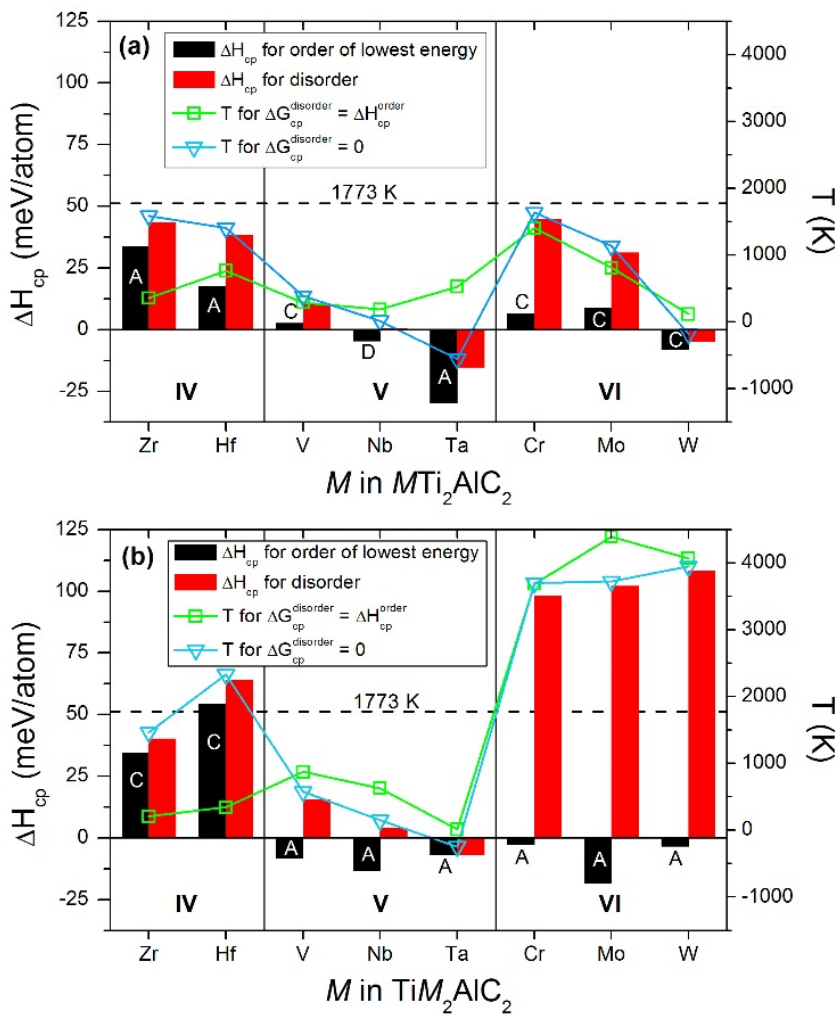

Fig.3 Formation enthalpy $\Delta H_{\text {cp }}$ for (a) $\mathrm{MTi}_{2} \mathrm{AlC}_{2}$ and (b) $\mathrm{TiM}_{2} \mathrm{AlC}_{2}$, for the ordered structure of lowest energy (black bar) and the disordered structure (red bar), together with the estimated temperature for which the disordered structure is stabilized, $T_{\Delta G=0}$ (open triangles), and the temperature above which the disordered structure is energetically favourable compared to the ordered one, $T_{\text {disorder }}$ (open squares). The dashed horizontal line represents a typical bulk synthesis temperature of $1773 \mathrm{~K}$.

\section{$\mathrm{Ti}_{2} \mathrm{M}_{2} \mathrm{AlC}_{3}$}

Fig. 4 shows $\Delta H_{\mathrm{cp}}$ for $\mathrm{Ti}_{2} \mathrm{M}_{2} \mathrm{AlC}_{3}$, for the layered ordered structures of lowest energy (black bars) and for a disordered structure (red bars). $T_{\text {disorder }}$ is plotted as open squares, showing the estimated temperature above which the disordered structure is energetically favourable compared to the ordered one. For $M=\mathrm{Nb}, \mathrm{Mo}$, and $\mathrm{W}$, stable ordered phases are indicated with $\Delta H_{\mathrm{cp}}^{\text {order }}<0$. However, for $M=\mathrm{Nb}, T_{\text {disorder }}$ is well below $1773 \mathrm{~K}$, i.e., a disordered structure is expected for typical synthesis conditions. As $T_{\text {disorder }} \geq 1870 \mathrm{~K}$ for $M=\mathrm{Mo}$, and $W$, ordered structures with $A$ type layering are expected experimentally. Furthermore, it should be noted that $\Delta H_{\mathrm{cp}}^{\text {order }}>0$ but small for $M=\mathrm{V}, \mathrm{Ta}$, and $\mathrm{Cr}(+2,+12$, and +3 $\mathrm{meV} /$ atom, respectively). Hence, for at least $\mathrm{V}$ and $\mathrm{Ta}$, the configurational entropy may decrease the free energy for the solid solutions, and make the disordered $\mathrm{Ti}_{2} \mathrm{M}_{2} \mathrm{AlC}_{3}$ energetically favourable and likely to be realized during synthesis.

Bulk synthesis of $\mathrm{Ti}_{2} \mathrm{Mo}_{2} \mathrm{AlC}_{3}$ has shown structures where the Wyckoff $4 \mathrm{f}$-site is mainly occupied by Ti and Wyckoff $4 \mathrm{e}$-site mainly by $\mathrm{Mo},{ }^{24}$ which is a configuration closely related to the fully ordered type A structure considered in this work. The predicted stable ordered $\mathrm{Ti}_{2} \mathrm{~W}_{2} \mathrm{AlC}_{2}$ and close to stable ordered $\mathrm{Ti}_{2} \mathrm{Cr}_{2} \mathrm{AlC}_{3}$ of type $\mathrm{A}$ have not yet been identified experimentally.
Table 4 Calculated formation enthalpy $\Delta H_{\mathrm{cp}}$ for $\mathrm{Ti}_{2} \mathrm{M}_{2} \mathrm{AlC}_{3}$ where $\mathrm{M}=\mathrm{Zr}, \mathrm{Hf}, \mathrm{V}, \mathrm{Nb}, \mathrm{Ta}$, $\mathrm{Cr}, \mathrm{Mo}, \mathrm{W}$, including ordered (type $\mathrm{A}$ and $\mathrm{B}$, shown in Fig. 1 with $M^{1}=\mathrm{Ti}$ and $M^{2}=M$ ) and disordered (SQS) distribution of $\mathrm{Ti}$ and $M$ on the $M$-site. The last column shows the identified set of most competing phases. See Table $\$ 9$ to $\$ 10$ for definition of considered spin configurations for $\mathrm{Ti}_{2} \mathrm{Cr}_{2} \mathrm{AlC}_{3}$

\begin{tabular}{|c|c|c|c|c|}
\hline \multirow{2}{*}{$M$} & \multicolumn{3}{|c|}{$\Delta H_{\mathrm{cp}}$ (meV/atom) } & \multirow[t]{2}{*}{ Identified set of most competing phases } \\
\hline & $A$ & B & sQS & \\
\hline $\mathrm{Zr}$ & 74 & 44 & 60 & $\mathrm{ZrC}, \mathrm{Ti}_{3} \mathrm{AlC}_{2}, \mathrm{Zr}_{4} \mathrm{AlC}_{3}$ \\
\hline $\mathrm{Hf}$ & 84 & 27 & 55 & $\mathrm{HfC}, \mathrm{Ti}_{2} \mathrm{AlC}$ \\
\hline V & 2 & 85 & 37 & $\mathrm{TiC}, \mathrm{TiV}_{2} \mathrm{AlC}_{2}$ \\
\hline $\mathrm{Nb}$ & -5 & 56 & 17 & $\mathrm{TiNb}_{2} \mathrm{AlC}_{2}(\mathrm{~A}), \mathrm{TiC}$ \\
\hline $\mathrm{Ta}$ & 12 & 17 & 4 & $\left(\mathrm{Ti}_{0.5} \mathrm{Ta}_{0.5}\right) \mathrm{C}, \mathrm{TaTi}_{2} \mathrm{AlC}_{2}(\mathrm{~A}), \mathrm{TiTa}_{2} \mathrm{AlC}_{2}(\mathrm{~A})$ \\
\hline $\mathrm{Cr}$ & $3^{a}$ & $203^{b}$ & $101^{\mathrm{c}}$ & $\mathrm{TiC}, \mathrm{Cr}_{2} \mathrm{AlC}$ \\
\hline Mo & -17 & 173 & 71 & $\mathrm{TiC}, \mathrm{TiMo}_{2} \mathrm{AlC}_{2}(\mathrm{~A})$ \\
\hline w & -16 & 134 & 40 & $\mathrm{TiW}_{2} \mathrm{AlC}_{2}(\mathrm{~A}), \mathrm{TiC}$ \\
\hline
\end{tabular}

a in-AFM1 spin configuration of lowest energy (FM and AFM2 within 1 meV/atom).

${ }^{b} \mathrm{NM}$ and in-AFM1 spin configurations are degenerate and of lowest energy. c FM spin configuration of lowest energy.

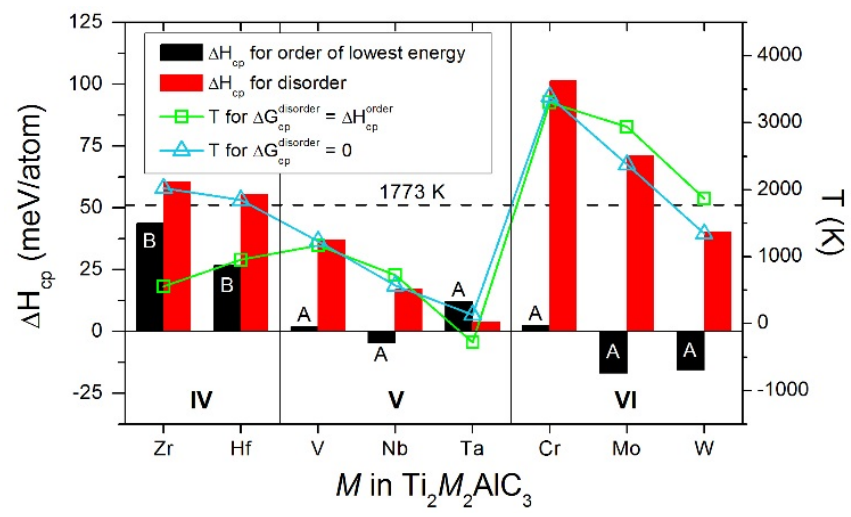

Fig. 4 Formation enthalpy $\Delta H_{\mathrm{cp}}$ for $\mathrm{Ti}_{2} \mathrm{M}_{2} \mathrm{AlC}_{3}$, for the ordered structure of lowest energy (black bar) and the disordered structure (red bar), together with the estimated temperature for which the disordered structure is stabilized, $T_{\Delta G=0}$ (open triangles), and the temperature above which the disordered structure is energetically favourable compared to the ordered one, $T_{\text {disorder }}$ (open squares).

Table 5 summarizes the results of our phase stability predictions for chemically ordered and disordered $(\mathrm{Ti}, M)_{n+1} \mathrm{AlC}_{n}$ phases, and can serve as a guide for experimental realization of known as well as new quaternary MAX phase alloys. The first column of phases displays ordered phases predicted to be stable at $0 \mathrm{~K}$, i.e., $\Delta H_{\mathrm{cp}}^{\text {order }}<0$. These are expected to be possible to realize experimentally, with either a chemically ordered or disordered distribution of $\mathrm{Ti}$ and $M$. Since synthesis is performed at elevated temperatures, a disordered structure may be energetically preferred over an ordered phase when $T_{\text {disorder }}<1773 \mathrm{~K}$, as shown in the second column of phases. It should be emphasized that an ordered phase, even if metastable with respect to a stable disordered structure, may be realized through processes including non-equilibrium conditions, such as thin film growth. There are also phases which are not stable in any form at $0 \mathrm{~K}$, i.e., $\Delta H_{\mathrm{cp}}>0$, that can be stabilized at elevated temperatures and possible to realize in 
a disordered form, as seen in the third column of phases in Table 5.

Table 5 Summary of known as well as new quaternary $(\mathrm{Ti}, M)_{n+1} \mathrm{AlC}_{n}$ phases expected to be realized experimentally; those predicted to be stable and ordered at $0 \mathrm{~K}$ $\left(\Delta H_{\mathrm{cp}}^{\text {order }}<0\right)$ or moderate temperatures, or those disordered due to $T_{\text {disorder }}<1773 \mathrm{~K}$, or those disordered $\left(\Delta H_{\mathrm{cp}}>0\right)$ but stabilized with temperature, $T_{\Delta G=0}<1773 \mathrm{~K}$.

\begin{tabular}{|c|c|c|c|}
\hline \multirow[b]{2}{*}{$n$} & \multicolumn{2}{|c|}{$\Delta H_{\mathrm{cp}}^{\text {order }}<0$ at $0 \mathrm{~K}$} & \multirow{2}{*}{$\begin{array}{l}\Delta H_{\mathrm{cp}}^{\text {order }}>0 \text { at } 0 \mathrm{~K} \\
\text { Disordered phases } \\
\text { stabilized by temperature }\end{array}$} \\
\hline & Stable ordered phases & $\begin{array}{l}\text { Order } \rightarrow \text { disorder for } \\
T_{\text {disorder }}<1773 \mathrm{~K}\end{array}$ & \\
\hline \multirow{3}{*}{1} & & & TiMAIC (M = Zr, Hf) \\
\hline & TiMAIC $(M=\mathrm{V}, \mathrm{Nb}, \mathrm{Ta})$ & TiMAIC $(M=\mathrm{V}, \mathrm{Nb}, \mathrm{Ta})$ & \\
\hline & & & TiMAIC $(M=C r, M o, W)$ \\
\hline \multirow{3}{*}{2} & & & $\mathrm{MTi}_{2} \mathrm{AlC}_{2}(M=\mathrm{Zr}, \mathrm{Hf})$ \\
\hline & $\mathrm{MTi}_{2} \mathrm{AlC}_{2}(M=\mathrm{Nb}, \mathrm{Ta})$ & $\mathrm{MTi}_{2} \mathrm{AlC}_{2}(M=\mathrm{Nb}, \mathrm{Ta})$ & $M \mathrm{Mi}_{2} \mathrm{AlC}_{2}(M=\mathrm{V})$ \\
\hline & $M \mathrm{Ti}_{2} \mathrm{AlC}_{2}(M=\mathrm{W})$ & $M \mathrm{Mi}_{2} \mathrm{AlC}_{2}(M=\mathrm{W})$ & $M \mathrm{Ti}_{2} \mathrm{AlC}_{2}(M=\mathrm{Cr}, \mathrm{Mo})$ \\
\hline \multirow{3}{*}{2} & & & $\mathrm{TiM}_{2} \mathrm{AlC}_{2} \quad(M=\mathrm{Zr})$ \\
\hline & $\mathrm{TiM}_{2} \mathrm{AlC}_{2}(M=\mathrm{V}, \mathrm{Nb}, \mathrm{Ta})$ & $\mathrm{Ti}_{2} \mathrm{AlC}_{2}(M=\mathrm{V}, \mathrm{Nb}, \mathrm{Ta})$ & \\
\hline & $\mathrm{TiM}_{2} \mathrm{AlC}_{2}(M=\mathrm{Cr}, \mathrm{Mo}, \mathrm{W})$ & & \\
\hline \multirow{2}{*}{3} & $\mathrm{Ti}_{2} M_{2} \mathrm{AlC}_{3}(M=\mathrm{Nb})$ & $\mathrm{Ti}_{2} M_{2} \mathrm{AlC}_{3}(M=\mathrm{Nb})$ & $\mathrm{Ti}_{2} M_{2} \mathrm{AlC}_{3}(M=\mathrm{V}, \mathrm{Ta})$ \\
\hline & $\mathrm{Ti}_{2} \mathrm{M}_{2} \mathrm{AlC}_{3}(M=\mathrm{Mo}, \mathrm{W})$ & & \\
\hline
\end{tabular}

\subsection{The origin of layered ordered structures}

Evident from Table 5 and Fig. 2 to 4 is that $M$ from group $V$ and VI form layered ordered structures in $(\mathrm{Ti}, M)_{n+1} \mathrm{AlC}_{n}$ for $n \geq 2$ and $T_{\text {disorder }}>1773 \mathrm{~K}$. The following section will elaborate on the origin behind the formation of chemical order/disorder in quaternary MAX phase alloys, and hence the discussion will include experimentally known as well as hypothetical MAX phases. It should be stressed that the discussion here focus on stability with respect to order/disorder and possible reasons for such formations, and not on absolute stability, i.e. whether or not a phase is stable with respect to competing phases. First, the atomic stacking of $M_{n+1} \mathrm{AlC}_{n}$ and its subunit $M C$ will be explored, followed by analysis of the quaternary $(\mathrm{Ti}, M)_{n+1} \mathrm{AlC}_{n}$ phases.

\section{Atomic stacking of MC}

$M_{n+1} X_{n}$ is a sub unit of the $M_{n+1} A X_{n}$ phases with an $A b C$ stacking (not to be mixed with the notation for A, B, C, D, E, or F type structures referred to in Fig. 1 to 4 and Table 1 to 4 ) of $M$ and $X$ atoms, see panel (a) in Fig. S11 to S14. To clearly distinct between different stacking positions used for $M, A$, and $X$ atoms, the following notation are used: $A, B, C$ for $M, \underline{A}, \underline{B}, \underline{C}$ for $A$, and $a, b, c$ for $X$. The AbC stacking of $M$ and $X$ can also be found along the 111 direction of $\mathrm{NaCl}$ as seen in Fig. S11(a). $\mathrm{NaCl}$ is also the type structure for many $M X$ binaries when $M$ is from group IV and V. However, for group VI, there exists no stable $M C$ binary with an $\mathrm{AbCaBc}$ stacking. Instead, other atomic stackings are preferred, e.g., WC with an Ab stacking.

To investigate the possible influence of $M$ and $X$ stacking on the stability of the $M_{n+1} A X_{n}$ phases we initially considered six different atomic stackings of the $M C$ binaries as illustrated in
Fig. S11. Shown in Fig. 5 is the formation energy $\Delta E_{\mathrm{f}}$ for $M C$, i.e., energy for $M C$ with respect to the energy of the single elements, with different atomic stacking of $M$ and $C$. For group IV $(M=T i$, $\mathrm{Zr}, \mathrm{Hf}$ ) the $\mathrm{AbCaBc}$-stacking $(\mathrm{NaCl})$ is found with lowest energy whereas the Ab-stacking (WC) is the least stable among those considered. For group $\mathrm{V}(\mathrm{M}=\mathrm{V}, \mathrm{Nb}, \mathrm{Ta})$ there are three different stacking of lowest energy depending on the volume; $\mathrm{AbCaBc}$
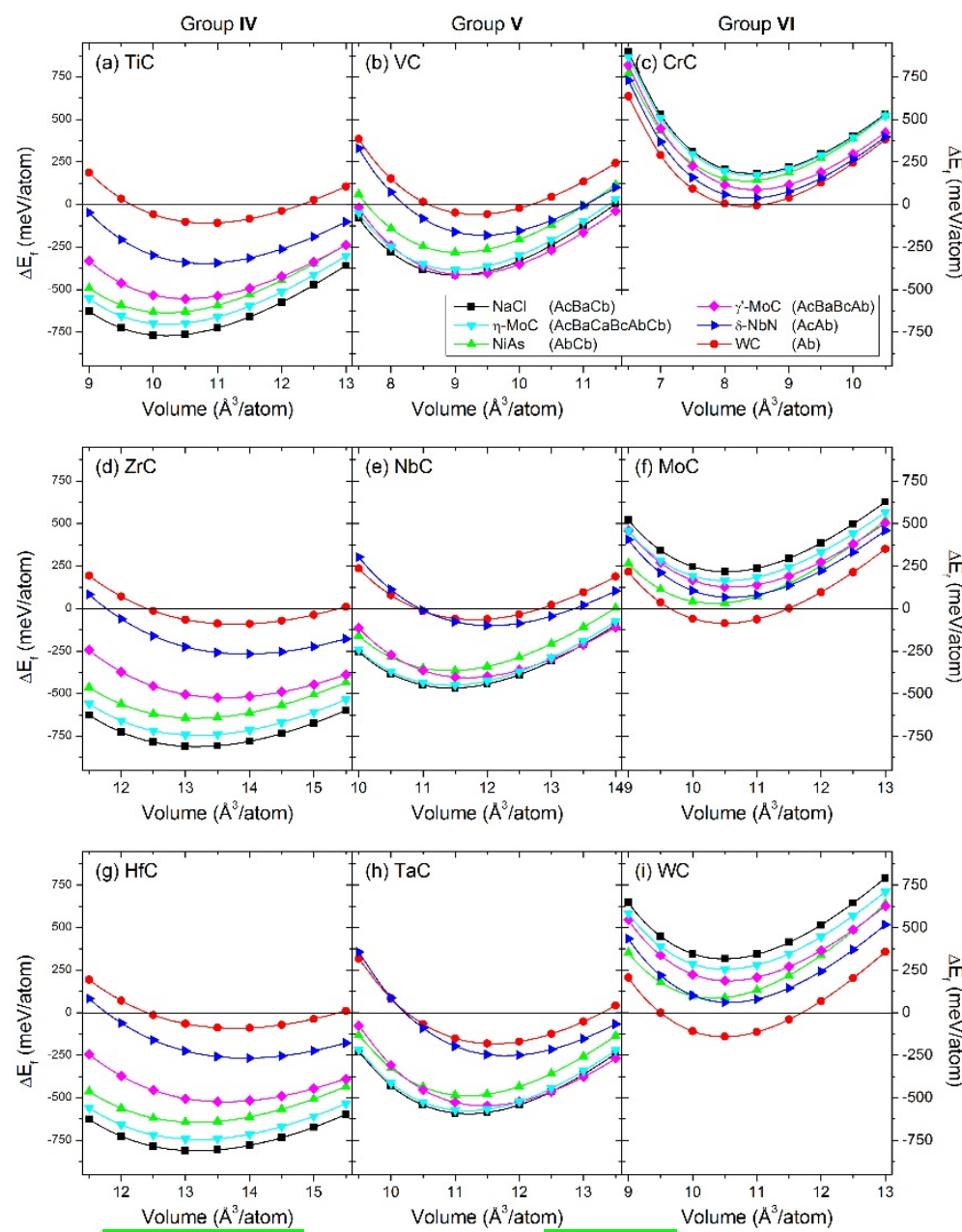

$(\mathrm{NaCl}), \mathrm{AcBaCaBcAbCb}(\eta-\mathrm{MoC})$, and $\mathrm{AcBaBcAb}\left(\gamma^{\prime}-\mathrm{MoC}\right)$, whereas $A b(W C)$ and $A c A b(\delta-N b N)$ stacking are found with highest energy. The result for group $\mathrm{VI}(M=\mathrm{Cr}$, Mo, W) show that the stacking of lowest energy is $A b$ (WC) while the least stable is $\mathrm{AbCaBc}(\mathrm{NaCl})$. As an $\mathrm{AbCaBc}$ atomic stacking is energetically preferred for $M$ from group IV and $V$, the corresponding formation of the MAX phases can therefore be expected. Correspondingly, as group VI does not energetically favour $\mathrm{AbCaBc}$-stacking, there is no energy gain in crystallizing into the MAX phase structure. In the literature we do find MAX phases from all three groups, but only group IV and $V$ form $M_{n+1} \mathrm{AlC}_{n}$ phases with $n \geq 2$.

\section{Atomic stacking of $\mathrm{M}_{\mathrm{n}+1} \mathrm{AlC}_{\mathrm{n}}$}

We have also considered different atomic stacking of $M, A l$, and $C$ in $M_{n+1} A_{C} C_{n}$, as illustrated in Fig. S12 to S14. When the 
stacking of element $A$ is varied for a fixed atomic stacking of $M$ and $X$, there is no significant change in energy, while the energy is more sensitive to different stacking of $M$ and $X$. The results are similar within a group, and for brevity, Ti, $\mathrm{V}$, and Mo are chosen as representatives of $M$ from group IV, V, and VI, respectively. The choice is based upon already synthesized MAX phases within two of these systems, i.e., for $M$ equal to Ti and $\mathrm{V}$.

Fig. 6 shows the formation enthalpy $\Delta H_{\mathrm{cp}}$ for selected atomic stacking of $M_{n+1} \mathrm{AlC}_{n}(n=1-3)$ versus volume. See Fig. S5 for all considered stacking sequences. The MAX phase structure (black filled squares) is stable for all $n$ for Ti and V, but only for $n=1$ for Mo. Instead, for $n \geq 2$, the Ab stacking of $M$ and $X(n=2$ and 3$)$ or the AbCbCbA stacking of $M$ and $X(n=3)$, see Fig. S13 and S14, respectively, are of lowest energy with the common feature of having $C$ atoms directly on top of each other. The MAX phase stacking is the least stable for $n \geq 2$, and energetically, the difference between $A b$ and MAX phase stacking is 60 and $111 \mathrm{meV} /$ atom for $n=2$ and 3, respectively. However, even though the non-MAX phase stackings are of lowest energy for Mo and $n \geq 2$, none are predicted stable since $\Delta H_{\mathrm{cp}}>0$.

For $\mathrm{Mo}_{n+1} \mathrm{AlC}_{n}$ the MAX phase stacking sequence of carbon is energetically expensive. One way to bypass this is by
$\left(C_{\text {vac }}^{\text {order }}\right)$ was also taken into consideration where every $3^{\text {rd }}$ carbon atom at the Wyckoff 2a-site is replaced by a vacancy. ${ }^{45}$, ${ }^{46}$ For $M=$ Mo, $C_{\text {vac }}^{\text {disorder }}$ results in a stabilization for $n=2$ and 3 , though with no effect for $n=1$. However, $\Delta H_{\text {cp }}$ remains positive for all $n$. Correspondingly, for $C_{\mathrm{vac}}^{\text {order }}$, then $\Delta H_{\mathrm{cp}}$ decreases from +171 to $+101 \mathrm{meV} /$ atom. For Ti and V, $C_{\text {vac }}^{\text {disorder }}$ only results in an increased energy, whereas formation of $C_{\mathrm{vac}}^{\text {order }}$ is preferred for $\mathrm{V}$, with a decrease of $\Delta H_{\mathrm{cp}}$ from +12 to $12 \mathrm{meV} /$ atom. These results suggest that formation of carbon vacancies can be used as one possible route to lower the energy of the system, and hence possibly increase the phase stability. For Mo-based phases any $C$ site is beneficial, whereas the Wyckoff 2a-site is preferred for $\mathrm{V}_{4} \mathrm{AlC}_{3}$. This has recently been theoretically and experimentally demonstrated also for $\mathrm{Nb}_{4} \mathrm{AlC}_{3} .{ }^{46}$

\section{Atomic stacking of quaternary ordered MAX phases}

The formation enthalpy $\Delta H_{\mathrm{cp}}$ for ordered layers of type $\mathrm{A}$ of $\mathrm{MTi}_{2} \mathrm{AlC}_{2}$ and $\mathrm{TiM}_{2} \mathrm{AlC}_{2}$ with different stacking sequences and configurations including carbon vacancies is shown in Fig. 7, where $V$ and $M o$ are again chosen as representatives of $M$ from group $\mathrm{V}$ and $\mathrm{VI}$, respectively. $\mathrm{VTi}_{2} \mathrm{AlC}_{2}, \mathrm{TiV}_{2} \mathrm{AlC}_{2}, \mathrm{MoTi}_{2} \mathrm{AlC}_{2}$, and $\mathrm{TiMo}_{2} \mathrm{AlC}_{2}$ are all of type $A$ layering, with the MAX phase
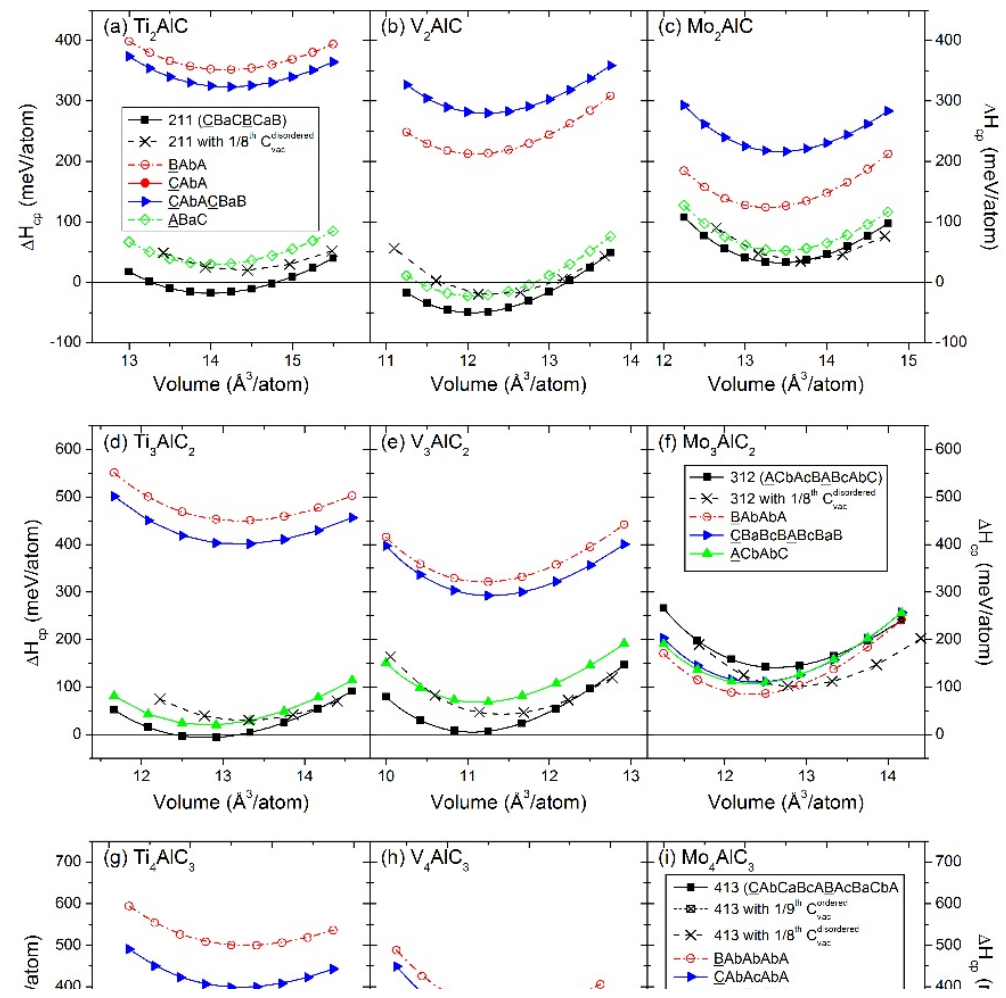

Fig. 6 Formation enthalpy $\Delta H_{\text {cp }}$ for selected atomic stacking sequences of $M_{n+1} \mathrm{AlC}_{n}(n=1-3)$ where $M=\mathrm{Ti}, \mathrm{V}$, and Mo. For the MAX phase stacking (black symbols), disordered and ordered carbon vacancies have also been modelled for $n=1-3$ and $n=3$, respectively.

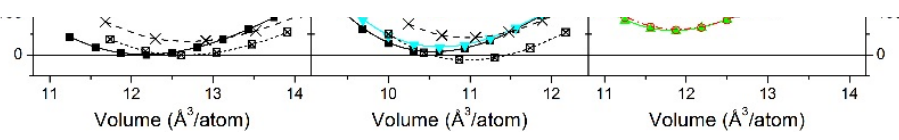

formation of carbon vacancies. We have modelled this for $n=1$ stacking being of lowest energy. Comparing to $\mathrm{Mo}_{3} \mathrm{AlC}_{2} \mathrm{where}$ - 3 using a disordered distribution of $12.5 \%$ carbon vacancies $\left(C_{\mathrm{vac}}^{\text {disorder }}\right)$. For $n=3$, an ordered distribution of $11 \%$ vacancies

an AbAbA stacking of Mo and $C$ is preferred, see Fig. 6(f), the substitution of Mo with $\mathrm{Ti}$ on the Wyckoff 2a-site to form 
$\mathrm{TiMo}_{2} \mathrm{AlC}_{2}$ (type A) apparently change the energetically preferred stacking.

The corresponding calculations have also been performed for $\mathrm{Ti}_{2} \mathrm{M}_{2} \mathrm{AlC}_{3}$, see Fig. 8, and the change in preferred stacking is evident also for $\mathrm{Ti}_{2} \mathrm{Mo}_{2} \mathrm{AlC}_{3}$ (type $\mathrm{A}$ ) as shown in Fig. 8(d), in comparison with $\mathrm{Mo}_{4} \mathrm{AlC}_{3}$ as shown in Fig. 6(i). However, for $\mathrm{Ti}_{2} \mathrm{Mo}_{2} \mathrm{AlC}_{3}$ (type $\mathrm{B}$ ) in Fig. 8(c), see schematic in Fig 1, the MAX phase stacking is not of lowest energy. Also notice that an ordered configuration of carbon vacancies is found to promote a decrease in $\Delta H_{\mathrm{cp}}$ for both $\mathrm{Ti}_{2} \mathrm{~V}_{2} \mathrm{AlC}_{3}$ and $\mathrm{Ti}_{2} \mathrm{Mo}_{2} \mathrm{AlC}_{3}$ of type B order.
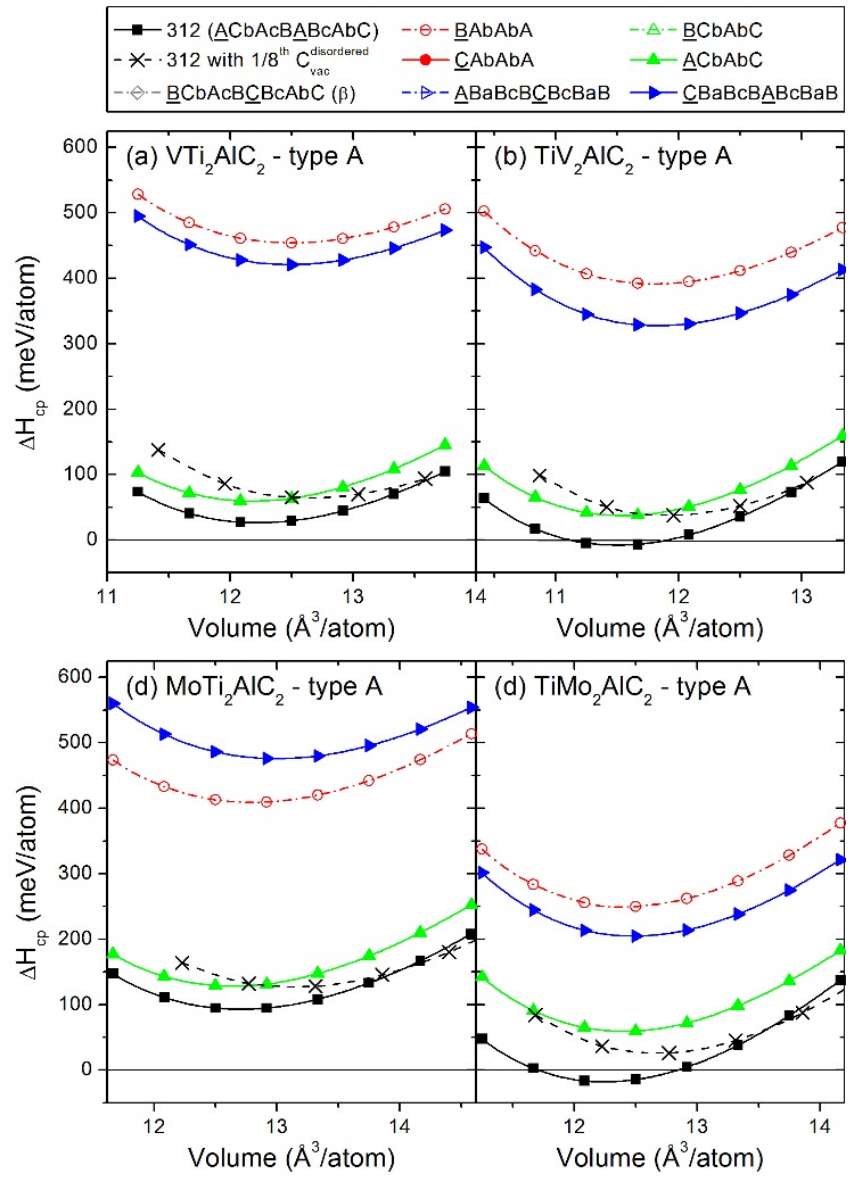

Fig. 7 Formation enthalpy $\Delta H_{\text {cp }}$ for selected atomic stacking sequences of ordered (a) VTi2AIC2, (b) TiV2AIC2, (c) MoTi2AIC2, and (d) TiMo2AIC2, with type $A$ layering. For the MAX phase stacking, disordered carbon vacancies have also been considered $(X)$.
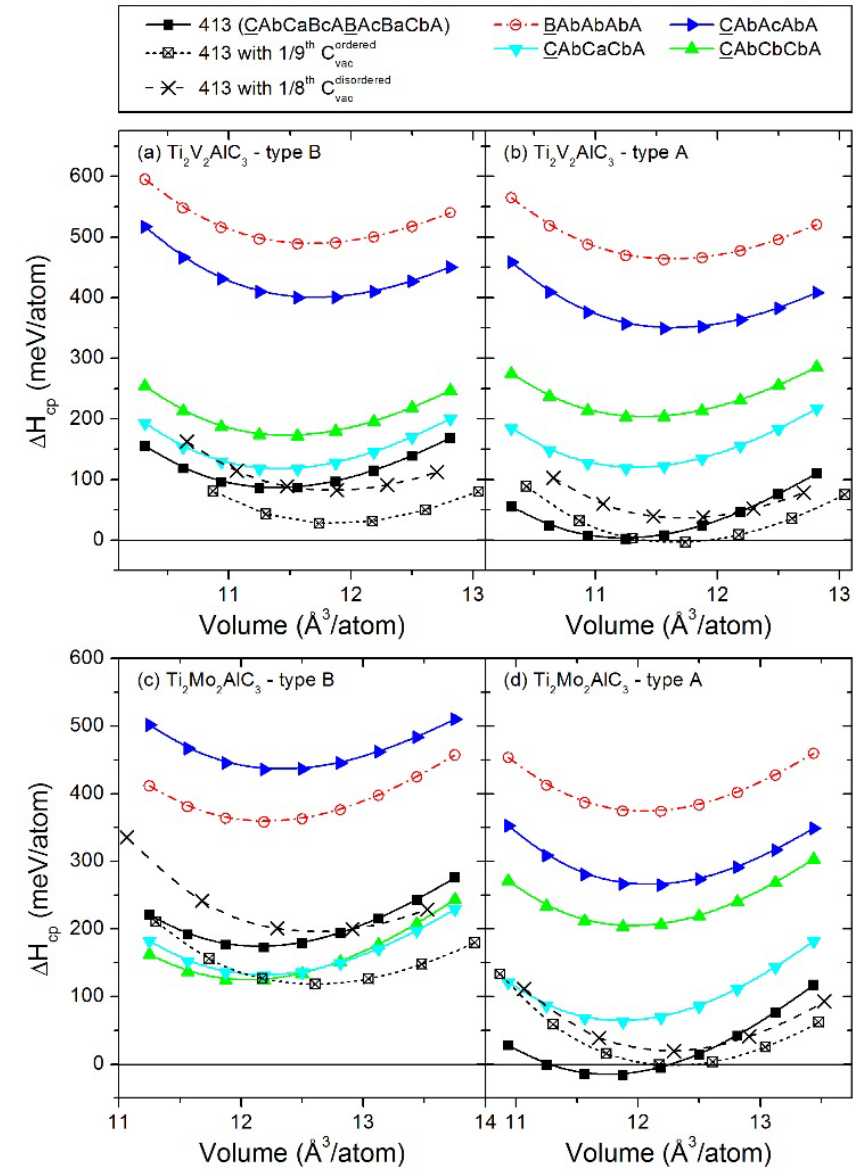

Fig. 8 Formation enthalpy $\Delta H_{\text {cp }}$ for selected atomic stacking sequences of ordered $\mathrm{Ti}_{2} \mathrm{~V}_{2} \mathrm{AlC}_{3}$ of (a) type $\mathrm{B}$ and (b) type $\mathrm{A}$, and $\mathrm{Ti}_{2} \mathrm{Mo}_{2} \mathrm{AlC}_{3}$ of (c) type $\mathrm{B}$ and (d) type $A$. For the MAX phase stacking, disordered $(X)$ and ordered ( $\square$ ) carbon vacancies have also been considered

Our results for $\mathrm{MoC}$, ordered $\mathrm{TiMo}_{2} \mathrm{AlC}_{2}$ and $\mathrm{Ti}_{2} \mathrm{Mo}_{2} \mathrm{AlC}_{3}$ (the latter two of type $A$ layering), supports the assumption made by Babak et al. ${ }^{24}$ that having Mo atoms surrounded by $C$ in a face-centred configuration is energetically unfavourable. However, the assumption made is not valid for the AbAbAbA stacking of type $\mathrm{B}$ layered $\mathrm{Ti}_{2} \mathrm{Mo}_{2} \mathrm{AlC}_{3}$, red circles in Fig. 8(c), which is rather high in energy even though the atomic stacking of Mo and $C$ is of the same kind as for low energy WC typestructure of MoC as seen in Fig. 5(f). Hence, having Mo atoms surrounded by $C$ in a face-centred configuration may be energetically unfavourable, but it cannot fully explain why, e.g., the calculated formation enthalpy of $\mathrm{TiMo}_{2} \mathrm{AlC}_{2}$ (type $\mathrm{A}$ ) is very low $\left(\Delta H_{\mathrm{cp}}=-18 \mathrm{meV} /\right.$ atom $)$ compared to $\mathrm{Ti}_{3} \mathrm{AlC}_{2},\left(\Delta H_{\mathrm{cp}}=-6\right.$ meV/atom) and $\mathrm{Mo}_{3} \mathrm{AlC}_{2}$ with either $\mathrm{MAX}$ phase stacking $\left(\Delta H_{c p}=+141 \mathrm{meV} /\right.$ atom $)$ or AbAbA stacking $\left(\Delta H_{\mathrm{cp}}=+85\right.$ meV/atom). In other words, formation of ordered $\mathrm{TiMo}_{2} \mathrm{AlC}_{2}$ (type A) cannot simply be explained by breaking the unfavourable $A B C$-stacking of $\mathrm{Mo}$ and $\mathrm{C}$ in $\mathrm{Mo}_{3} \mathrm{AlC}_{2}$ by substituting $\mathrm{Mo}$ at Wyckoff position $2 \mathrm{a}$ with $\mathrm{Ti}$. The same argument can also be made for $\mathrm{Ti}_{2} \mathrm{Mo}_{2} \mathrm{AlC}_{3}$.

The origin may, at least in part, be the different electronegativity of Ti (1.54) and Mo (2.16) as seen in Fig. 9(a). We have therefore performed Bader analysis to obtain the charge of each atom in $M_{3} \mathrm{AlC}_{2}, \mathrm{Ti}_{2} \mathrm{AlC}_{2}$ (type $\mathrm{A}$ ), $M_{4} \mathrm{AlC}$, and $\mathrm{Ti}_{2} \mathrm{M}_{2} \mathrm{AlC}_{2}$ (type A), for $M=\mathrm{Zr}, \mathrm{Hf}, \mathrm{V}, \mathrm{Nb}, \mathrm{Ta}, \mathrm{Cr}$, Mo, W. Fig. 9(b- 
e) shows the atomic Bader charge of $M, A l$, and $C$. The overall trend is that the highly electronegative $C$ is always negatively charged, i.e. with a surplus of electrons, $M$ is positively charged, i.e. electron deficient, with $M$ at Wyckoff $2 a$-site in 312 or $M$ at Wyckoff $4 \mathrm{f}$-site in 413 phases being more positive than $M$ at Wyckoff $4 \mathrm{f}$-site in 312 or $M$ at Wyckoff 4 e-site in 413 . This can be related to the carbon layers on both sides of $M$ at $2 a-$ or $4 \mathrm{f}$ site in 312 or 413 , respectively. $\mathrm{Al}$, on the other hand, is negatively charged for phases with $M$ from group IV, close to neutral when $M$ is from group $V$, and positive when $M$ is from group VI.

These trends can be correlated to the different electronegativity's of $M$ as shown in Fig. 9(a), where $M$ from group IV ( $\mathrm{Ti}, \mathrm{Zr}, \mathrm{Hf})$ is less electronegative than $\mathrm{Al}, M$ from Group $\mathrm{V}(\mathrm{Nb}, \mathrm{Ta}, \mathrm{V})$ is close to or less electronegative than $\mathrm{Al}$, and $\mathrm{M}$ from group $\mathrm{VI}(\mathrm{Cr}, \mathrm{Mo}, \mathrm{W})$ are all more electronegative than $\mathrm{Al}$.

To investigate how fewer electrons at and close to Al may have an influence on the low energy of layered ordered structures with $M$ from group $\mathrm{VI}$, the electronic structure and chemical bonding was evaluated. The total and atomic density of states (DOS) of $\mathrm{Ti}_{3} \mathrm{AlC}_{2} \mathrm{M}_{3} \mathrm{AlC}_{2}$ and $\mathrm{TiM}_{2} \mathrm{AlC}_{2}$ (type A), with $M=\mathrm{V}$ and $\mathrm{Mo}$, are shown in Fig. 10 $(\mathrm{a}-\mathrm{e})$, where the vertical line indicates the Fermi level $E_{\mathrm{f}}$. Overall, the presented DOS can be divided into several parts; (i) the peak at low energies, from -14 to $-9 \mathrm{eV}$, can mainly be attributed to localized C-s electrons, (ii) between -9 and $-6 \mathrm{eV}$, localized Al-s states dominate, (iii) the bonding states of $M-d$ and C- $p$ are found between -6 and $-2 \mathrm{eV}$, (iv) from -4 and up to $E_{\mathrm{f}}$, the bonding states of $M(4 \mathrm{f})-d$ and Al-p electrons can be found, and ( $v$ ) the states at $E_{f}$ originate primarily from $M-d$, and in particular from $M(4 f)$. From the DOS curves in panel (a) and (c), it is clear that $\mathrm{Ti}_{3} \mathrm{AlC}_{2}$ and $\mathrm{V}_{3} \mathrm{AlC}_{2}$ have close resemblance, though the states of the latter is shifted down in energy due to the extra electron of V. Both are found with the Fermi level $E_{f}$ located in a valley, indicating that the bonding valence bands are completely filled. Going to $\mathrm{Mo}_{3} \mathrm{AlC}_{2}$ in panel (e), the bonding peaks of $M-d$, Al-p, and C- $p$ are shifted towards lower energy due to an increased number of valence electrons. $E_{f}$ is no longer located in a local minima, and is instead found in a region implying occupation of antibonding states, consistent with a predicted reduced stability evident from $\Delta H_{\mathrm{cp}}=-6,+5$, and $+141 \mathrm{meV} /$ atom for $M=\mathrm{Zr}, \mathrm{Nb}$, and $\mathrm{Mo}$ in $\mathrm{M}_{3} \mathrm{AlC}_{2}$, respectively. For $\mathrm{TiV}_{2} \mathrm{AlC}_{2}$, the DOS is not affected much as compared to $\mathrm{Ti}_{3} \mathrm{AlC}_{2}$ and $\mathrm{V}_{3} \mathrm{AlC}_{2}$. However, when $\mathrm{Mo}(2 \mathrm{a})$ is substituted with $\mathrm{Ti}$ in $\mathrm{Mo}_{3} \mathrm{AlC}_{2}$, the number of states at $E_{f}$ is reduced by almost $50 \%$, and $C-s$ and bonding states of $M-d$ and $C-p$ are shifted to lower energies. Compared to $\mathrm{Ti}_{3} \mathrm{AlC}_{2}$, the bonding states of $M(4 \mathrm{f})-d$ and $\mathrm{Al}-p$ in $\mathrm{TiMo}_{2} \mathrm{AlC}_{2}$ are found at lower energies. This results are an indication of the reduced total energy for type $A$ layering of the $\mathrm{TiMo}_{2} \mathrm{AlC}_{2}$ phase as compared to $\mathrm{Ti}_{3} \mathrm{AlC}_{2}$ and $\mathrm{Mo}_{3} \mathrm{AlC}_{2}$.

Bonding analysis in terms of the projected crystal orbital Hamiltonian population ( $\mathrm{pCOHP}$ ) have been performed for nine interactions in $\mathrm{M}_{3} \mathrm{AlC}_{2}$ and $\mathrm{Ti}_{2} \mathrm{AlC}_{2}$ (type $\mathrm{A}$ layering) for $\mathrm{M}=\mathrm{V}$ and $\mathrm{Mo}$, see schematic in Fig. 10. In order to facilitate interpretation and to preserve the analogy to crystal orbital overlap population (COOP) analysis, results are here presented as -pCOHP, rather than pCOHP. From the pCOHP curves in Fig. 10 it is clear that the nearest neighbor interactions of $M(2 a)-C$, $M(4 f)$, and $M(4 f)-A l$ are typically optimized for $M_{3} A_{l} C_{2}$ and $\mathrm{TiM}_{2} \mathrm{AlC}_{2}$, with bonding orbitals completely filled and antibonding orbitals empty below $E_{\mathrm{f}}$. The only exception is for $M(4 \mathrm{f})-\mathrm{C}$, for $M=\mathrm{V}$ and $\mathrm{Mo}$, which displays a small antibonding contribution close to $E_{\mathrm{f} .} M(2 \mathrm{a})-M(2 \mathrm{a})$ and $M(4 \mathrm{f})-M(4 \mathrm{f})$ in-plane interactions all have bonding orbitals completely filled and
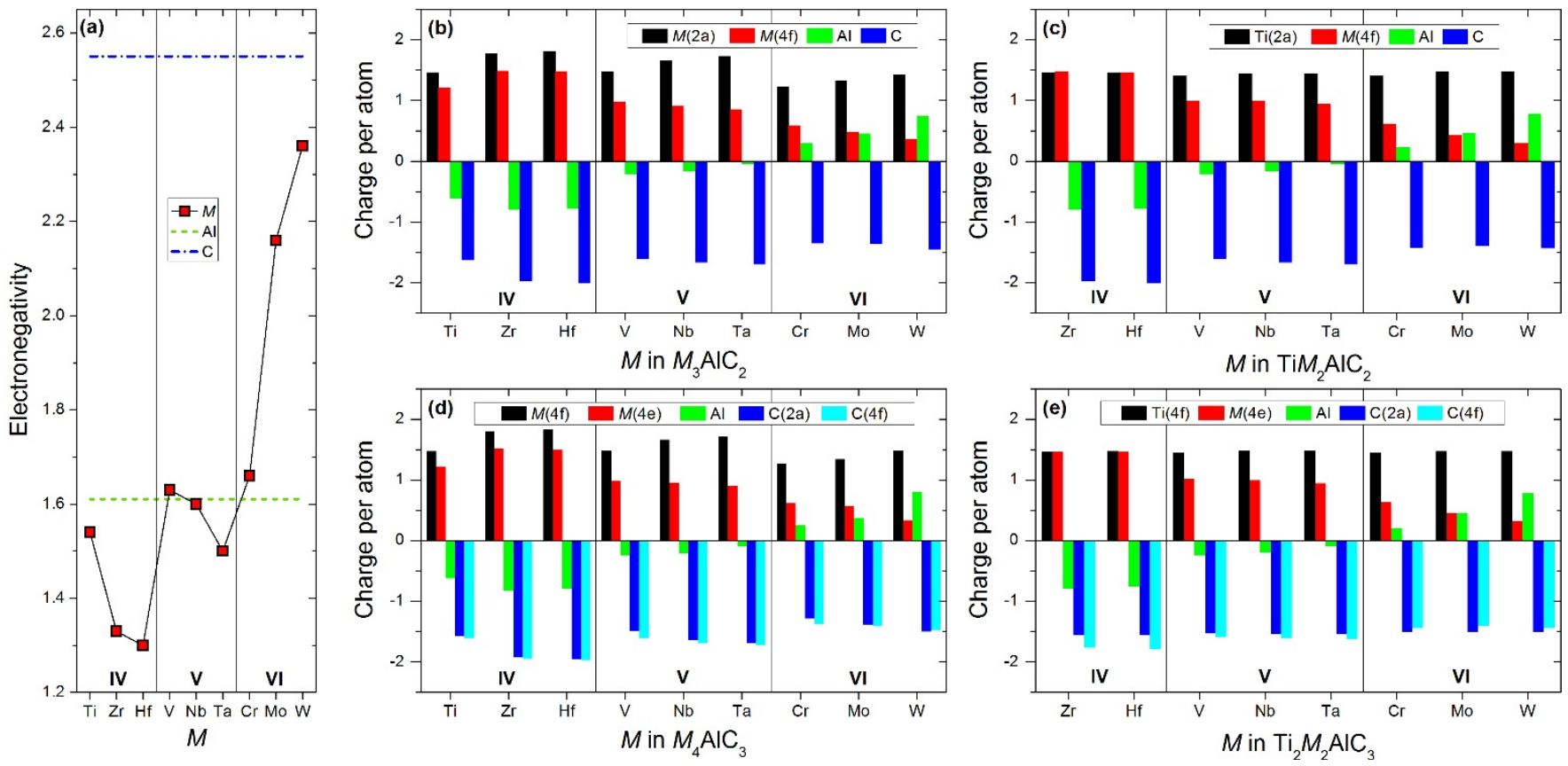

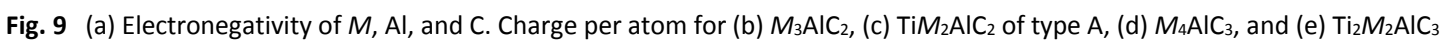
of type $A$ 

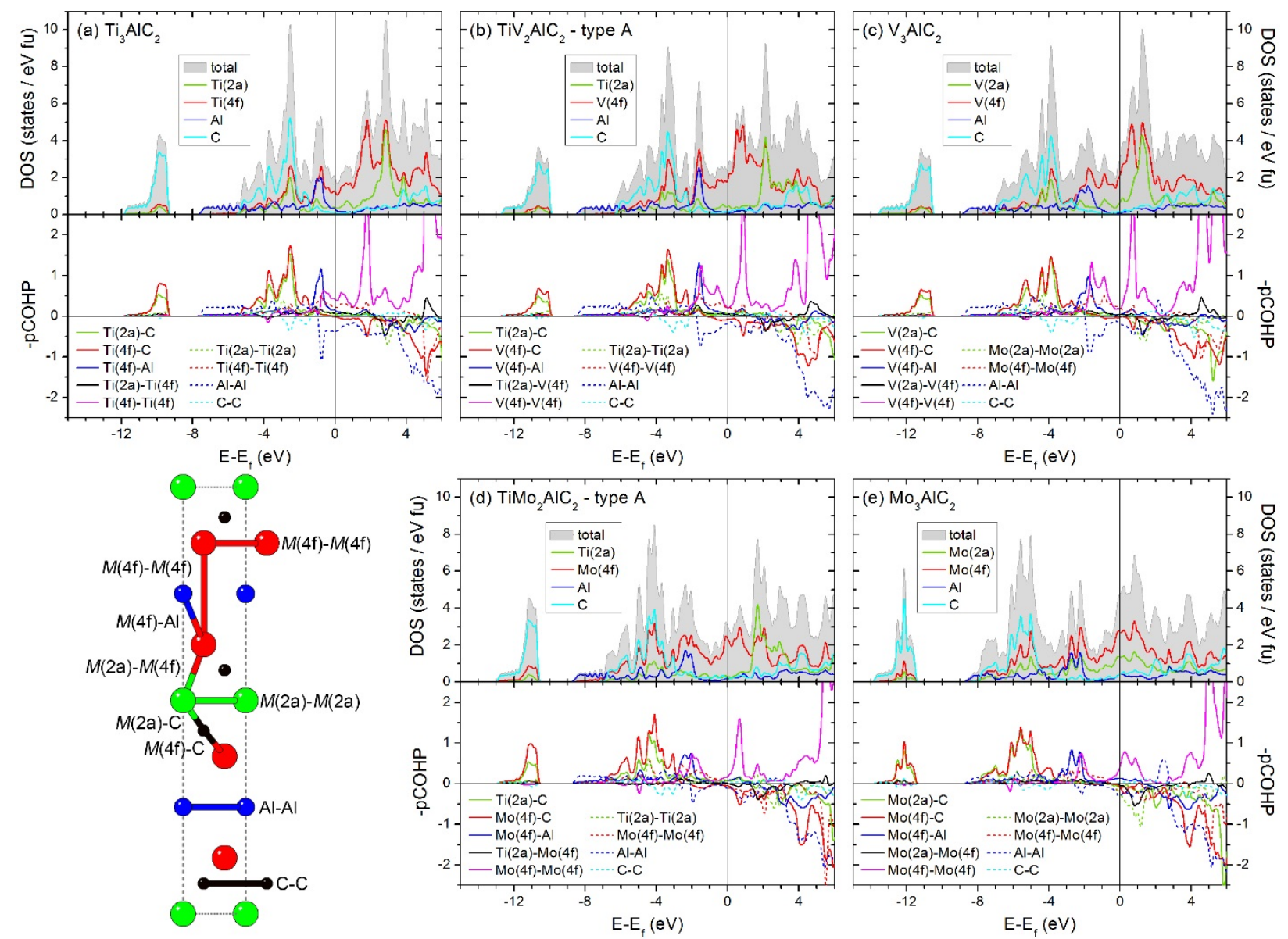

Fig. 10 Calculated total and atomic density of states (DOS) and projected crystal overlap Hamiltonian population (pCOHP) analysis for (a) $\mathrm{Ti}_{3} \mathrm{AlC}_{2}$, (b) $\mathrm{TiV}_{2} \mathrm{AlC}_{2}$ (type A), (c) $\mathrm{V}_{3} \mathrm{AlC}_{2}$, (d) $\mathrm{TiMo}_{2} \mathrm{AlC}_{2}$ (type A), and (e) $\mathrm{Mo}_{3} \mathrm{AlC}_{2}$. The schematic five out-of-plane and four inplane $\mathrm{pCOHP}$ interactions are shown at the bottom of panel $(\mathrm{a})-(\mathrm{e})$ with solid and dashed lines, respectively.

antibonding orbitals empty below $E_{\mathrm{f}}$. For $M=\mathrm{Ti}$ and $\mathrm{V}, \mathrm{C}-\mathrm{C}$ and especially $\mathrm{Al}-\mathrm{Al}$ in-plane interactions have filled antibonding states below $E_{f}$. These are also present for $M=$ Mo but much more reduced. For brevity, pCOHPs of $M_{4} \mathrm{AlC}_{3}$ and $\mathrm{Ti}_{2} \mathrm{M}_{2} \mathrm{AlC}_{3}$ are not shown here, as they show large resemblance with $M_{3} \mathrm{AlC}_{2}$ and $\mathrm{TiM}_{2} \mathrm{AlC}_{2}$, though the same arguments apply for these phases.

The low energy of ordered $\mathrm{TiM}_{2} \mathrm{AlC}_{2}$ (type $\mathrm{A}$ ) with $M$ from group $\mathrm{VI}$, can thus be related to; (i) $M$ atoms surrounded by $\mathrm{C}$ in a face-centered configuration is energetically unfavourable and substitution of $M(2 a)$ with Ti breaks this stacking, (ii) as $M$ have a higher electronegativity compared to $\mathrm{Al}$, the Al becomes more positively charged which results in fewer electrons available for populating the antibonding Al-Al interaction (which would increase the energy of the system), and (iii) bonding states are shifted to lower energies as compared to $\mathrm{Ti}_{3} \mathrm{AlC}_{2}$ without populating antibonding states, thus lowering the total energy of the system. Corresponding analysis of $\mathrm{Ti}_{2} \mathrm{M}_{2} \mathrm{AlC}_{3}(\mathrm{M}=\mathrm{Cr}$, Mo, $W$ ) reveals similar results and supports the statements above.

\subsection{Off-stoichiometry in ordered $\mathrm{M}^{\prime}{ }_{3-\mathrm{m}} \mathrm{M}_{\mathrm{m}} \mathrm{AlC}_{2}$}

Experimental evidence for $\mathrm{TiCr}_{2} \mathrm{AlC}_{2}$ has been reported, with 100 at\% $\mathrm{Ti}$ at Wyckoff $2 \mathrm{a}$ and 100 at\% $\mathrm{Cr}$ at Wyckoff 4f,22, 23 whereas off-stoichiometric quaternary phases have been reported for $\mathrm{Ti}_{1.5} \mathrm{Mo}_{1.5} \mathrm{AlC}_{2}$ and $\mathrm{V}_{1.5} \mathrm{Cr}_{1.5} \mathrm{AlC}_{2},{ }^{12,24}$ with 100 at\%
Ti or $\mathrm{V}$ at Wyckoff 2a and 75 at\% Mo or Cr at Wyckoff $4 \mathrm{f} \mathrm{(25} \mathrm{at \%}$ Ti or $\mathrm{V})$. These results raise the question how much it is possible to deviate from the $\mathrm{TiM}_{2} \mathrm{AlC}_{2}$ composition while still retaining an ordered, or a semi-ordered, structure with one of the Wyckoff sites (2a or $4 \mathrm{f}$ ) occupied by only one element.

To model this we constructed SQS supercells with a disordered distribution of $M$ atoms on one of the $M$ sites only. Fig. 11 shows the formation enthalpy $\Delta H_{\mathrm{cp}}$ at $0 \mathrm{~K}$ (solid symbols and solid lines) and Gibbs free energy $\Delta G_{\mathrm{cp}}$ at $1773 \mathrm{~K}$ (open symbols and dashed lines) as function $m$ in $M^{\prime}{ }_{3-m} M_{m} A_{I C} C_{2}$ where $M^{\prime}=\mathrm{Ti}, \mathrm{V}$, and $M=\mathrm{V}, \mathrm{Cr}$, Mo. For $\mathrm{Ti}_{3-m} \mathrm{~V}_{m} \mathrm{AlC}_{2}$ in panel (a), ordered and semi-ordered structures are found with lowest energy at $\mathrm{OK}$ for all $m$, whereas a disordered distribution of $\mathrm{Ti}$ and $\mathrm{V}$ is favoured at $1773 \mathrm{~K}$. For the other three quaternary systems the disordered structure is found at much higher energies and at $1773 \mathrm{~K}$, the ordered and semi-ordered structures are still the preferred ones. For comparison, the composition of synthesized ordered and semi-ordered structures of $\mathrm{TiCr}_{2} \mathrm{AlC}_{2},{ }^{22,}{ }^{23} \quad \mathrm{~V}_{1.5} \mathrm{Cr}_{1.5} \mathrm{AlC}_{2},{ }^{12}$ and $\mathrm{Ti}_{1.5} \mathrm{Mo}_{1.5} \mathrm{AlC}_{2}, 24$ are marked with a vertical solid line, which is data consistent with here presented calculations. This indicates that ordered layered phases can deviate slightly from "perfect" stoichiometry, i.e., deviate from only one atomic element at Wyckoff 2a (4f for $\mathrm{Ti}_{2} \mathrm{M}_{2} \mathrm{AlC}_{3}$ ) and/or $4 \mathrm{f}\left(4 \mathrm{e}\right.$ for $\mathrm{Ti}_{2} \mathrm{M}_{2} \mathrm{AlC}_{3}$ ), while still being stable. This may explain reported compositional 

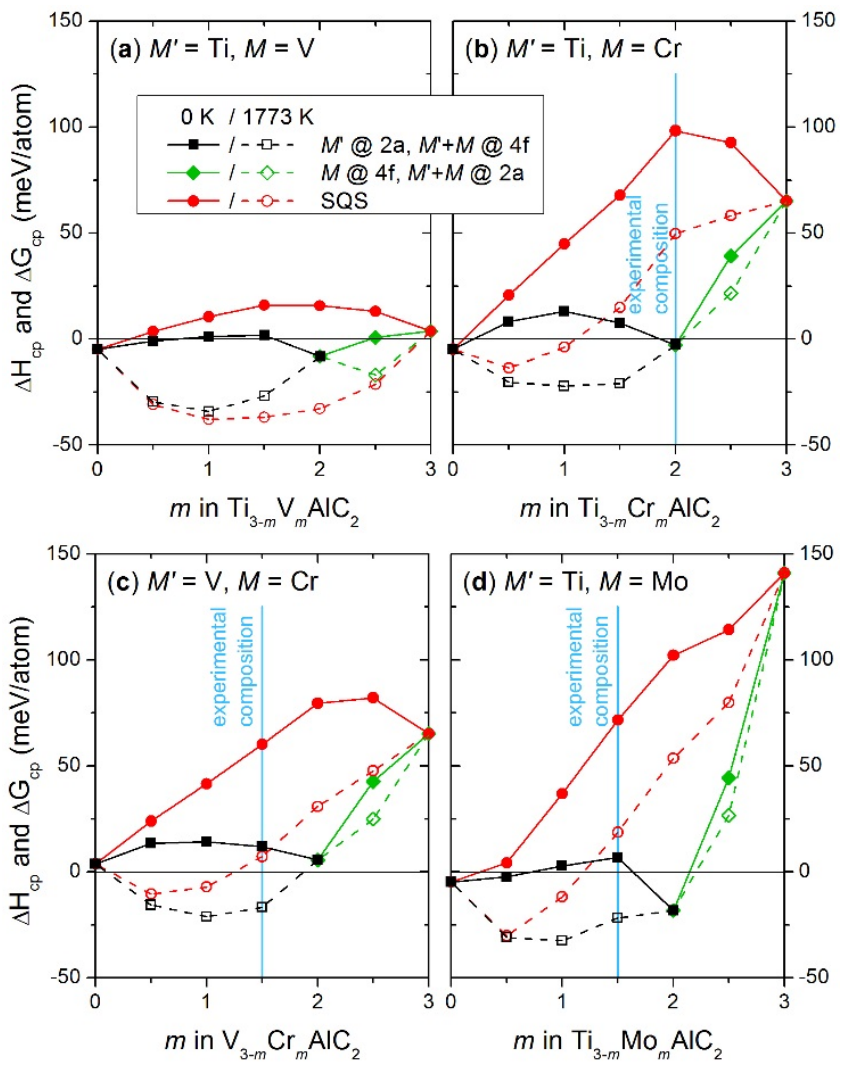

Fig. 11 Formation enthalpy $\Delta H_{\mathrm{cp}}$ at $0 \mathrm{~K}$ (solid symbols and solid lines) and Gibbs free energy $\Delta G_{\mathrm{cp}}$ at $1773 \mathrm{~K}$ (open symbols and dashed lines) for $M^{\prime}{ }_{3 .}$ ${ }_{m} M_{m} A_{I} C_{2}$ where $M^{\prime}=\mathrm{Ti}, \mathrm{V}$, and $M=\mathrm{V}, \mathrm{Cr}$, Mo, for semi-ordered layered structures and solid solutions (SQS). The vertical solid line represents experimentally obtained ordered or semi-ordered structures.

deviations from $\mathrm{TiM}_{2} \mathrm{AlC}_{2}$ and $\mathrm{Ti}_{2} \mathrm{M}_{2} \mathrm{AlC}_{3}$ for $\mathrm{V}_{1.5} \mathrm{Cr}_{1.5} \mathrm{AlC}_{2}{ }^{12}$, $\mathrm{V}_{2.2} \mathrm{Cr}_{1.8} \mathrm{AlC}_{3},{ }^{12} \quad \mathrm{Ti}_{1.5} \mathrm{Mo}_{1.5} \mathrm{AlC}_{2}{ }^{24} \quad \mathrm{Ti}_{2.2} \mathrm{Mo}_{1.8} \mathrm{AlC}_{3},{ }^{24}$ and $\mathrm{Ti}_{1.5} \mathrm{Cr}_{2.5} \mathrm{AlC}_{3} .{ }^{23}$ Caspi et al. ${ }^{12}$ showed that in $\mathrm{V}_{2.2} \mathrm{Cr}_{1.8} \mathrm{AlC}_{3}$ there was mixture of $\mathrm{V}$ and $\mathrm{Cr}$ with different concentrations at Wyckoff $4 \mathrm{f}$ ( 80 at\% $\mathrm{V}$ and 20 at\% $\mathrm{Cr}$ ) and $4 \mathrm{e}$ (30 at\% $\mathrm{V}$ and 70 at\% $\mathrm{Cr}$ ).

The recently discovered $\mathrm{TiCr}_{2} \mathrm{AlC}_{2}, \mathrm{Ti}_{1.5} \mathrm{Mo}_{1.5} \mathrm{AlC}_{2}$, $\mathrm{Ti}_{2} \mathrm{Mo}_{2} \mathrm{AlC}_{3}, \mathrm{~V}_{1.5} \mathrm{Cr}_{1.5} \mathrm{AlC}_{2}$, and here predicted stable phases of novel TiM $\mathrm{AlC}_{2}$ and $\mathrm{Ti}_{2} \mathrm{M}_{2} \mathrm{AlC}_{3}$ compositions, belong to a new family of chemically ordered quaternary MAX phases. These phases allow inclusion of elements in combinations previously not forming MAX phases, e.g., to date there are no $\mathrm{Mo}_{n+1} \mathrm{AIC}_{n}$ phases reported. These novel combinations can then be used to alter or add new properties to this family of laminated materials. This was demonstrated by Babak et al. ${ }^{24}$, showing that bulk, shear, and elastic moduli of $\mathrm{TiMo}_{2} \mathrm{AlC}_{2}$ and $\mathrm{Ti}_{2} \mathrm{Mo}_{2} \mathrm{AlC}_{3}$ were improved compared to the pure ternaries. Furthermore, $\mathrm{Al}$ is the A-group element in all realized ordered MAX phases to date, ${ }^{12,22-25}$ and it is also an element which can be readily etched in $\mathrm{HF}$ to form MXene. ${ }^{26}$ Recently, new ordered MXenes $\left(\mathrm{TiMo}_{2} \mathrm{C}_{2}, \mathrm{Ti}_{2} \mathrm{Mo}_{2} \mathrm{C}_{3}, \mathrm{TiCr}_{2} \mathrm{C}_{2}\right.$ ) were synthesized from ordered quaternary MAX phases, and even more hypothetical MXenes were theoretically suggested ${ }^{28}$. Still, an important aspect missing in the prediction of new MXenes is the evaluation of the parent material, which is the MAX phase. Reliable calculations for prediction of stability of new materials should include all competing phases in the system and not focus only on the energy of a phase with respect to its constituent atoms, as demonstrated in Ref. ${ }^{38}$.

\section{Conclusions}

We have performed a systematic theoretical study of phase stability of chemically ordered and disordered quaternary $(\mathrm{Ti}, M)_{n+1} \mathrm{AlC}_{n}(n=1-3)$ phases, where $M=\mathrm{Zr}$, Hf (group IV), $M$ $=\mathrm{V}, \mathrm{Ta}, \mathrm{Nb}$ (group $\mathrm{V}$ ), and $\mathrm{M}=\mathrm{Cr}, \mathrm{Mo}, \mathrm{W}$ (group $\mathrm{VI}$ ). At $0 \mathrm{~K}$, we predict layered ordered structures to be stable for $M$ from group $\mathrm{V}$ and $\mathrm{VI}$. Out of these, only $\mathrm{Ti}_{2} \mathrm{AlC}_{2}(M=\mathrm{Cr}, \mathrm{Mo}, \mathrm{W})$ and $\mathrm{Ti}_{2} \mathrm{M}_{2} \mathrm{AlC}_{2}(M=\mathrm{Mo}, \mathrm{W})$ are identified with an orderdisorder temperature $T_{\text {disorder }}>1773 \mathrm{~K}$ (typical bulk synthesis temperature) and hence likely to be chemically ordered if synthesized, while the others are found with $T_{\text {disorder }}<1773 \mathrm{~K}$ and therefore expected to have a chemically disordered distribution of $\mathrm{Ti}$ and $M$. It should be emphasized that a metastable ordered phase may very well be realized at nonequilibrium conditions through e.g. thin film deposition. Phases predicted to not be stable at $0 \mathrm{~K}$ can be stabilized at elevated temperatures in a chemically disordered form, being the case for group IV and $\mathrm{MTi}_{2} \mathrm{AlC}_{2}(M=\mathrm{V}, \mathrm{Cr}, \mathrm{Mo})$, and $\mathrm{Ti}_{2} \mathrm{M}_{2} \mathrm{AlC}_{3}(M=$ $\mathrm{V}, \mathrm{Ta})$. These results are in accordance with experimental findings of disordered $\left(\mathrm{Ti}_{0.5} \mathrm{~V}_{0.5}\right)_{2} \mathrm{AIC},\left(\mathrm{Ti}_{0.5} \mathrm{Nb}_{0.5}\right)_{2} \mathrm{AlC}$, and $\left(\mathrm{Ti}_{0.4} \mathrm{Ta}_{0.6}\right)_{2} \mathrm{AlC}, \quad\left(\mathrm{V}_{0.5} \mathrm{Ti}_{0.5}\right)_{3} \mathrm{AlC}_{2}$ and ordered $\mathrm{TiCr}_{2} \mathrm{AlC}_{2}$, $\mathrm{TiMo}_{2} \mathrm{AlC}_{2}, \mathrm{Ti}_{2} \mathrm{Mo}_{2} \mathrm{AlC}_{3}$. In addition to the here predicted stable disordered alloys, the predicted stable ordered $\mathrm{Ti}_{2} \mathrm{~W}_{2} \mathrm{AlC}_{2}$ and close to stable ordered $\mathrm{Ti}_{2} \mathrm{Cr}_{2} \mathrm{AlC}_{3}$ is yet to be experimentally verified. The driving force for the formation and stability of these layered and chemically ordered structures, with $M$ from group $\mathrm{V}$ and $\mathrm{VI}$, is at least in part explained by; (i) $M$ surrounded by $C$ in a face-centred configuration is energetically unfavourable when $M$ is from group $\mathrm{VI}$, and this is changed by substitution with $\mathrm{Ti}$, and (ii) $M$ from group $\mathrm{VI}$ have a larger electronegativity than $\mathrm{Al}$, and thus fewer electrons will be available for populating antibonding Al-Al orbitals. Adding a fourth element to form ordered quaternary MAX phases allows for new novel elemental combinations which can be used to add/tune new properties in this family of atomic laminates.

\section{Acknowledgements}

The research was funded by the European Research Council under the European Community Seventh Framework Program (FP7/2007-2013)/ERC Grant agreement no [258509]. J. R. acknowledges funding from the KAW Fellowship program, from the Swedish Research Council (VR) Grant No. 642-2013-8020, and from the Swedish Foundation of Strategic Research (SSF) Synergy Grant FUNCASE. The simulations were carried out using supercomputer resources provided by the Swedish National Infrastructure for Computing (SNIC) at the National Supercomputer Centre (NSC), the High Performance Computing Center North (HPC2N), and the PDC Center for High Performance Computing. 


\section{References}

1. P. Eklund, M. Beckers, U. Jansson, H. Högberg and L. Hultman, Thin Solid Films, 2010, 518, 1851-1878.

2. M. W. Barsoum and T. El-Raghy, Am. Scientist, 2001, 89, 334-343.

3. A. S. Ingason, A. Mockute, M. Dahlqvist, F. Magnus, S. Olafsson, U. B. Arnalds, B. Alling, I. A. Abrikosov, B. Hjörvarsson, P. O. Å. Persson and J. Rosen, Phys. Rev. Lett., 2013, 110, 195502.

4. R. Meshkian, A. S. Ingason, U. B. Arnalds, F. Magnus, J. Lu and J. Rosen, APL Materials, 2015, 3, 076102.

5. P. Eklund, M. Dahlqvist, O. Tengstrand, L. Hultman, J. Lu, N. Nedfors, U. Jansson and J. Rosén, Phys. Rev. Lett., 2012, 109, 035502.

6. A. S. Ingason, A. Petruhins, M. Dahlqvist, F. Magnus, A. Mockute, B. Alling, L. Hultman, I. A. Abrikosov, P. O. Å. Persson and J. Rosen, Mater. Res. Lett., 2014, 2, 89-93.

7. M. Dahlqvist, A. S. Ingason, B. Alling, F. Magnus, A. Thore, A. Petruhins, A. Mockute, U. B. Arnalds, M. H. Sahlberg, B. Hjörvarsson, I. A. Abrikosov and J. Rosen, submitted, 2015.

8. J. C. Schuster, H. Nowotny and C. Vaccaro, J. Solid State Chem., 1980, 32, 213-219.

9. H. Nowotny, P. Rogl and J. C. Schuster, J. Solid State Chem., 1982, 44, 126-133.

10. M. W. Barsoum, I. Salama, T. El-Raghy, J. Golczewski, H. J. Seifert, F. Aldinger, W. D. Porter and H. Wang, Metall. Mater. Trans. A, 2002, 33, 2775-2779.

11. C. L. Yeh and W. J. Yang, Ceram. Int., 2013, 39, 7537-7544.

12. E. a. N. Caspi, P. Chartier, F. Porcher, F. Damay and T. Cabioc'h, Mater. Res. Lett., 2015, 3, 100-106.

13. S. Lin, P. Tong, B. S. Wang, Y. N. Huang, W. J. Lu, D. F. Shao, B. C. Zhao, W. H. Song and Y. P. Sun, J. Appl. Phys., 2013, 113, 053502 053501-053506.

14. A. Mockute, M. Dahlqvist, J. Emmerlich, L. Hultman, J. M. Schneider, P. O. Å. Persson and J. Rosen, Phys. Rev. B, 2013, 87, 094113.

15. Z. Liu, T. Waki, Y. Tabata and H. Nakamura, Phys. Rev. B, 2014, 89, $054435054431-054436$.

16. A. Mockute, J. Lu, E. J. Moon, M. Yan, B. Anasori, S. J. May, M. W. Barsoum and J. Rosen, Mater. Res. Lett., 2014, 3, 16-22.

17. Q. Z. Tao, C. F. Hu, S. Lin, H. B. Zhang, F. Z. Li, D. Qu, M. L. Wu, Y. P. Sun, Y. Sakka and M. W. Barsoum, Mater. Res. Lett., 2014, 4, 192-198.

18. A. Petruhins, A. S. Ingason, J. Lu, F. Magnus, S. Olafsson and J. Rosen, J. Mater. Sci., 2015, 50, 4495-4502.

19. R. Salikhov, A. S. Semisalova, A. Petruhins, A. S. Ingason, J. Rosen, U. Wiedwald and M. Farle, Mater. Res. Lett., 2015, 3, 156-160.

20. S. Kerdsongpanya, K. Buchholt, O. Tengstrand, J. Lu, J. Jensen, L. Hultman and P. Eklund, J. Appl. Phys., 2011, 110, 053516.

21. M. Naguib, G. W. Bentzel, J. Shah, J. Halim, E. N. Caspi, J. Lu, L. Hultman and M. W. Barsoum, Mater. Res. Lett., 2014, 2, 233-240.

22. Z. Liu, E. Wu, J. Wang, Y. Qian, H. Xiang, X. Li, Q. Jin, G. Sun, X. Chen, J. Wang and M. Li, Acta Mater., 2014, 73, 186-193.

23. Z. Liu, L. Zheng, L. Sun, Y. Qian, J. Wang and M. Li, J. Am. Ceram. Soc., 2014, 97, 67-69.

24. B. Anasori, M. Dahlqvist, J. Halim, E. J. Moon, J. Lu, B. C. Hosler, C. E. a. N., S. J. May, L. Hultman, P. Eklund, J. Rosén and M. W. Barsoum, J. Appl. Phys., 2015, 118, 094304.

25. B. Anasori, J. Halim, J. Lu, C. A. Voigt, L. Hultman and M. W. Barsoum, Scripta Mater., 2015, 101, 5-7.

26. M. Naguib, V. N. Mochalin, M. W. Barsoum and Y. Gogotsi, Adv. Mater., 2014, 26, 992-1005.
27. R. Meshkian, L.-Å. Näslund, J. Halim, J. Lu, M. W. Barsoum and J. Rosen, Scripta Mater., 2015, 108, 147-150.

28. B. Anasori, Y. Xie, M. Beidaghi, J. Lu, B. C. Hosler, L. Hultman, P. R. C. Kent, Y. Gogotsi and M. W. Barsoum, ACS Nano, 2015, DOI: http://dx.doi.org/10.1021/acsnano.5b03591.

29. P. E. Blöchl, Phys. Rev. B, 1994, 50, 17953-17979.

30. G. Kresse and D. Joubert, Phys. Rev. B, 1999, 59, 1758-1775.

31. G. Kresse and J. Hafner, Phys. Rev. B, 1993, 47, 558-561.

32. G. Kresse and J. Furthmüller, Comput. Mater. Sci., 1996, 6, 15-50.

33. G. Kresse and J. Furthmüller, Phys. Rev. B, 1996, 54, 1116911186.

34. J. P. Perdew, K. Burke and M. Ernzerhof, Phys. Rev. Lett., 1996, 77, 3865-3868.

35. H. J. Monkhorst and J. D. Pack, Phys. Rev. B, 1976, 13, 5188-5192.

36. A. Zunger, S. H. Wei, L. G. Ferreira and J. E. Bernard, Phys. Rev. Lett., 1990, 65, 353-356.

37. M. Dahlqvist, B. Alling, I. A. Abrikosov and J. Rosén, Phys. Rev. B, 2010, 81, 024111.

38. M. Dahlqvist, B. Alling and J. Rosén, Phys. Rev. B, 2010, 81, 220102.

39. A. Mockute, P. O. Å. Persson, F. Magnus, A. S. Ingason, S. Olafsson, L. Hultman and J. Rosen, Phys. Status Solidi Rapid Res. Lett., 2014, 8, 420-423.

40. S. Maintz, V. L. Deringer, A. L. Tchougréeff and R. Dronskowski, Journal of Computational Chemistry, 2013, 34, 2557-2567.

41. V. L. Deringer, A. L. Tchougréeff and R. Dronskowski, The Journal of Physical Chemistry A, 2011, 115, 5461-5466.

42. R. Dronskowski and P. E. Bloechl, The Journal of Physical Chemistry, 1993, 97, 8617-8624.

43. V. Presser, M. Naguib, L. Chaput, A. Togo, G. Hug and M. W. Barsoum, Journal of Raman Spectroscopy, 2012, 43, 168-172.

44. I. Salama, T. El-Raghy and M. W. Barsoum, J. Alloys Compd., 2002, 347, 271-278.

45. J. Etzkorn, M. Ade and H. Hillebrecht, Inorg. Chem., 2007, 46, 7646-7653.

46. H. Zhang, T. Hu, X. Wang, Z. Li, M. Hu, E. Wu and Y. Zhou, Scientific Reports, 2015, 5, 14192. 